\title{
Chalcogen bonding in crystalline diselenides and selenocyanates: from molecules of pharmaceutical interest to conducting materials
}

\author{
Marc Fourmigué* and Arun Dhaka \\ Univ Rennes, CNRS, ISCR (Institut des Sciences Chimiques de Rennes) UMR 6226, 35042 \\ Rennes, France. Email: marc.fourmigue@univ-rennes1.fr
}

Keywords: diselenide, selenocyanate, $\sigma$-hole interaction, chalcogen bond, antioxidant, conducting materials, anion recognition

\begin{abstract}
Organic diselenides are nowadays investigated for pharmaceutical applications, as well as in material science in molecular (semi)conductors. In both application's domains, their interactions with Lewis bases, in solution or in the solid state, has been shown to play a crucial role in their biological activity or in their electronic structure. The current comprehensive survey of reported crystal structures of organic diselenides demonstrates the recurrent setting of intermolecular as well as intramolecular chalcogen bonding interactions $(\mathrm{ChB})$ between the selenium atoms acting as $\mathrm{ChB}$ donors and Lewis bases. These interactions take place along the two covalent bonds of the selenium atom. In diselenides, stronger interactions are found in the prolongation of the $\mathrm{Se}-\mathrm{Se}$ bond than in the prolongation of the $\mathrm{C}-\mathrm{Se}$ bond. Charge activation of $\mathrm{ChB}$ is demonstrated in dicationic diselenides or in cation radical salts of 1,2-diselenole derivatives. This survey is extended to the structures of organic selenocyanates whose crystal structures reflect also the presence of two $\sigma$-holes, with a much stronger one in the prolongation of the NC-Se bond. Such ChB interactions of selenocyanates with polytopic Lewis bases or with halide anions open novel strategies in crystal engineering and anion recognition strategies.
\end{abstract}




\section{Contents}

1. Introduction

2. ChB interactions of diselenides with Lewis bases

2.1. Intermolecular $\mathrm{ChB}$ interactions

2.2. Intramolecular $\mathrm{ChB}$ interactions

2.2.1. 1,5 ChB interactions

2.2.2. $1,4 \mathrm{ChB}$ interactions

2.3. Charge activation of $\mathrm{ChB}$

2.3.1. Charge activation in ionic systems

2.3.2. Charge activation in cation radical salts

3. ChB interactions in selenocyanates

3.1. Intramolecular interactions

3.2. Intermolecular interactions

3.2.1. The recurrent Se••NC motif

3.2.2. Other examples

3.3. Selenocyanate co-crystals with neutral Lewis bases

3.4. Selenocyanate adducts with halides and other anions

4. Conclusions and perspectives 


\section{Introduction}

Selenium is recognized as an essential trace element involved in various physiological processes, and a deficiency of selenium in organisms can cause serious diseases. ${ }^{1,2}$ As a consequence, there has been a continuing increased interest during the last few decades in developing new synthetic organoselenium compounds (Ebselen for example) ${ }^{3}$ with antiinflammatory, anti-oxidant and cytoprotective activity. It has been found that in many compounds involving a divalent selenium, a non-bonding interaction with another heteroatom $(\mathrm{O}, \mathrm{N}, \ldots)$ was taking place, in the prolongation of the $\mathrm{C}-\mathrm{Se}$ bonds. These interactions were reviewed ${ }^{4}$ in 2010 and were shown to provide many interesting advantages such as: (i) high bioactivity as well as specific redox activity, (ii) conformational rigidity toward chirality transfer, (iii) synthetic models for the glutathione peroxidase family of enzymes. They were described to derive from the interaction of nucleophiles with the low-lying antibonding orbital of the selenium moiety $\left(\sigma^{*} \mathrm{C}-\mathrm{Se}\right)$, providing the selenium atom an electrophilic character.

Paralleling these observations, a new theme has also emerged in the last twenty years, first in crystal engineering, the so-called $\sigma$-hole interactions. They were originally described in the heavier halogens (X) and characterized in halogenated molecules by a specific geometry of intermolecular X $\bullet \bullet X$ contacts, ${ }^{5,6}$ described as halogen bonding (XB). ${ }^{7}$ These contacts where the halogen atom acts as an electrophile toward a Lewis base (LB) are characterized by short $\mathrm{X} \bullet \bullet$ LB distances (notably shorter than the sum of van der Waals radii) ${ }^{8}$ and high directionality $\left(\mathrm{C}-\mathrm{X} \bullet \bullet \mathrm{LB}\right.$ angles close to $\left.180^{\circ}\right)$. They are the consequence of polarization of the electron density around the halogen atom, with a charge depletion (the $\sigma$-hole) in the prolongation of the $\mathrm{C}-\mathrm{X}$ bond. This charge-depleted area leads to an electrostatic interaction with LB. ${ }^{9}$ Stronger interactions involve a higher degree of charge transfer, bringing then some covalency to the halogen bonding, as found for example in the reaction of $\mathrm{I}_{2}$ (XB donor) with $\mathrm{I}^{-}$(XB acceptor) to give $\mathrm{I}_{3}{ }^{-10}$, or in the $\mathrm{N}$-iodosaccharin adducts with pyridines. ${ }^{11}$ Halogen bonding is now accepted as a general concept, ${ }^{12,13}$ the term itself has been recognized by IUPAC ${ }^{14}$ and the whole domain extensively reviewed. ${ }^{15} \mathrm{XB}$ has found today many applications, in crystal engineering, anion recognition and transport, organocatalysis, conducting and magnetic materials, luminescent molecules as well as in biochemistry. It was rapidly recognized that the concept of $\sigma$-hole was not restricted to halogen atoms but could be extended to other elements able to exhibit such an electron cloud polarization and $\sigma$-hole apparition, ${ }^{16}$ leading to the concepts of chalcogen bonding $(\mathrm{ChB})$, pnictogen bonding $(\mathrm{PnB})$ and even tetrel bonding $(\operatorname{TrB}) .{ }^{17}$ If one concentrates on the chalcogen bonding, the main difference with $\mathrm{XB}$ is the presence of now 
two $\sigma$-holes on the chalcogen atom, each of them in the prolongation of the covalent bonds to selenium atom, as illustrated in Figure 1 for the activated sulfur derivatives $\mathrm{SCl}_{2}$ and octafluorothiophane. ${ }^{18,19}$

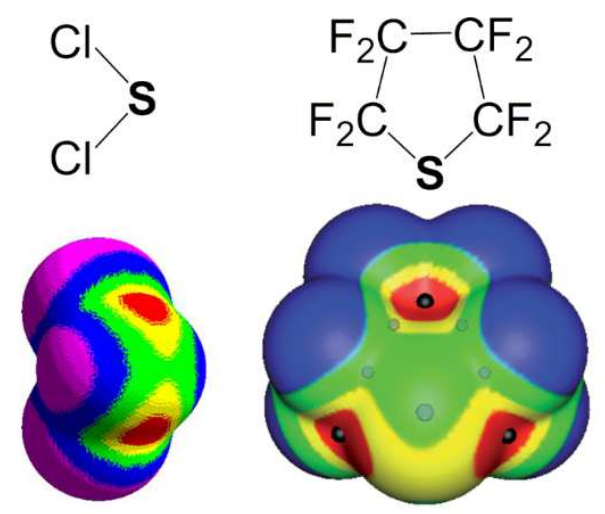

Figure 1. Calculated B3PW91/6-31G** electrostatic potentials of $\mathrm{SCl}_{2}$ (left) and octafluorothiophane (right), computed on the 0.001 electron $/ \mathrm{bohr}^{3}$ contour of the electronic density. The extrema values $\mathrm{V}_{\mathrm{S} \text {,max }}$ of the electropositive (red) area on the sulfur atom are 25.1 and $41 \mathrm{kcal} \mathrm{mol}^{-1}$ in $\mathrm{SCl}_{2}$ and octafluorothiophane respectively. Adapted with permission from (i) ref. 18 (Copyright 2008 Springer) for $\mathrm{SCl}_{2}$, (ii) from ref. 19 (Copyright 2017 The Royal Society of Chemistry) for octafluorothiophane.

Among organoselenium compounds, organic diselenides $\mathrm{R}_{2} \mathrm{Se}_{2}$ have been extensively investigated, and especially those involved in similar intramolecular $\mathrm{Se} \bullet \bullet(\mathrm{O}, \mathrm{N}, \mathrm{S}, \ldots)$ nonbonding interactions, resulting in organoselenium species with increased hydrolytic and thermal stability, conformational rigidity and better specific properties, e.g. antioxidant activity. In order to highlight the trends observed in $\mathrm{ChB}$ interactions in such compounds, we have undertaken a systematic study, based on the reported X-ray crystal structures (CSD Version 5.40 November 2018), of organic diselenides and the analogous organic selenocyanates. Only organic $\mathrm{Se}^{(\mathrm{II})}$ compounds were analyzed excluding all metallic complexes as well as $\mathrm{Se}^{(\mathrm{IV})}$ species. Besides strong and recurrent intramolecular $\mathrm{ChB}$ in diselenides, intermolecular $\mathrm{ChB}$ was also specifically identified in cationic diselenides, whose positive charge is expected to enhance $\mathrm{ChB}$ toward the anionic counterions acting as $\mathrm{ChB}$ acceptors. Examples were found also in mixed-valence systems prepared for their conducting properties. Finally, this search has been extended to the much smaller family of structurally characterized organic selenocyanate derivatives. The strong electron-withdrawing character of the $\mathrm{CN}$ moiety induces a polarization of the selenium atom with the enhancement of one $\sigma$-hole (in the prolongation of the NC-Se 
bond) over the other, leading to even stronger intra- and intermolecular ChB interactions. In the following, the $\mathrm{ChB}$ interactions will be characterized by the so-called reduction ratio (RR), which is the ratio of the actual Se••X distance over the sum of the van der Waals radii of interacting atoms, as taken from Bondi. ${ }^{8}$

\section{ChB interactions of diselenides with Lewis bases}

Among the hundreds of organic diselenides structurally characterized, those involving only these selenium atoms as heteroatoms are often characterized by numerous Se••re intermolecular contacts, most often close to the normal van des Waals distance $(2 \times 1.90 \AA=$ $3.80 \AA$ A). They will not be detailed here. Specific $\sigma$-hole interactions are more clearly identified in those molecules bearing functional groups with Lewis base character. Among them, we will mention few examples involving intermolecular interactions, followed by the extensive series that show intramolecular $\mathrm{ChB}$ interactions. The third series of compounds is found in cationic systems whose positive charge indeed activates the $\mathrm{ChB}$ interactions with neighboring counter ions.

\subsection{Intermolecular ChB interactions in diselenides}

The diselenocyanate molecule $\mathrm{NCSe}-\mathrm{SeCN}$ provides a very good example of $\mathrm{ChB}$ in diselenides. The calculated electrostatic surface potential (Figure 2) clearly shows the four $\sigma$ holes one can anticipate, two in the prolongation of the Se-Se bond, and two in the prolongation of the C-Se bonds. ${ }^{20}$ Its crystal structure (Figure 3, XUNHOF) ${ }^{21}$ shows indeed that they are interacting all four with the nitrogen lone pair of neighboring molecules. As shown in Table 1, the interactions are short and highly directional. One co-crystal of NCSe-SeCN with the bromide salt $\mathrm{PhNMe}_{3}{ }^{+}, \mathrm{Br}^{-}$has been also reported. ${ }^{22}$ As shown in Figure 3, all four $\sigma$-holes are again interacting, with bromide anion or nitrogen atom, with very short distances (Table 1) and strong linearity. These two examples give us the essential tools to analyze the role of $\mathrm{ChB}$ in crystal structures of diselenides and selenocyanates. 

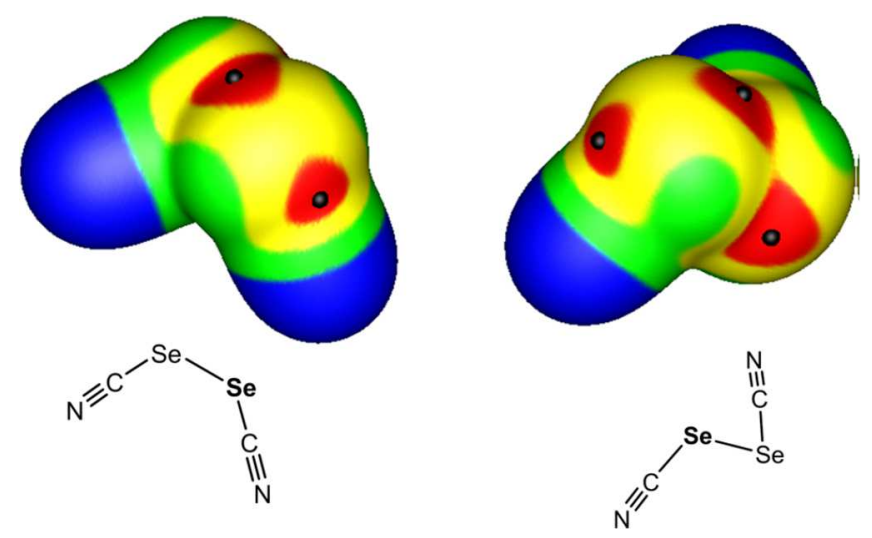

Figure 2. Computed electrostatic potentials on the 0.001 au molecular surface of dicyanodiselenide. Reproduced from Ref 20, with authorization of ACS.

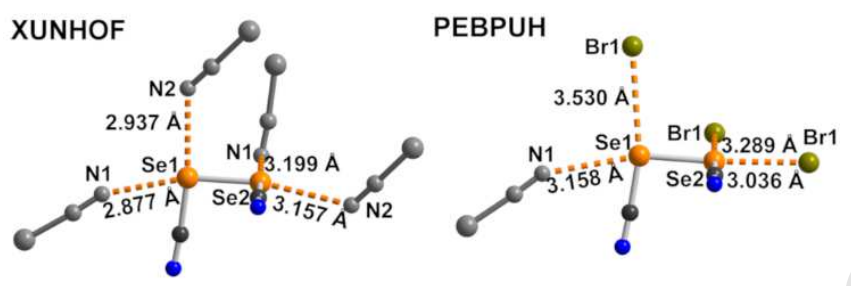

Figure 3. Detail of the interaction network around $\mathrm{NCSe}-\mathrm{SeCN}$, in the molecule alone (XUNHOF) and in its co-crystal with $\mathrm{PhNMe}_{3}{ }^{+} \mathrm{Br}^{-}$(PEBPUH). Only half of the surrounding $\mathrm{NCSe}-\mathrm{SeCN}$ molecules are shown in grey.

Table 1. Structural characteristics of ChB in XUNHOF and PEBPUH.

\begin{tabular}{|c|c|c|c|c|}
\hline XUNHOF & Se•••N $(\AA)$ & RR & \multicolumn{2}{|c|}{ Directionality $\left(^{\circ}\right)$} \\
\hline $\mathrm{Se} 1 \bullet \bullet N 1^{\mathrm{i}}$ & 2.877 & 0.83 & $\mathrm{Se} 2-\mathrm{Se} 1 \bullet \bullet \mathrm{N} 1^{\mathrm{i}}$ & 164.3 \\
\hline $\mathrm{Se} 1 \bullet \bullet \bullet N 2^{\mathrm{ii}}$ & 2.937 & 0.85 & $\mathrm{C} 1-\mathrm{Se} 1 \cdot \bullet \cdot \mathrm{N} 2^{\mathrm{ii}}$ & 172.9 \\
\hline $\mathrm{Se} 2 \cdot \bullet \mathrm{N} 1^{\mathrm{iii}}$ & 3.199 & 0.93 & $\mathrm{C} 2-\mathrm{Se} 2 \cdot \bullet \bullet N 1^{\mathrm{iii}}$ & 178.4 \\
\hline $\mathrm{Se} 2 \cdot \bullet \mathrm{N} 2^{\mathrm{iv}}$ & 3.157 & 0.91 & $\mathrm{Se} 1-\mathrm{Se} 2 \cdot \bullet \bullet N 2^{\mathrm{iv}}$ & 165.3 \\
\hline PEBPUH & $\mathrm{Se} \bullet \bullet \operatorname{Br}(\mathrm{N})(\AA)$ & RR & \multicolumn{2}{|c|}{ Directionality $\left({ }^{\circ}\right)$} \\
\hline $\mathrm{Se} 1 \bullet \bullet \mathrm{N} 1^{\mathrm{v}}$ & 3.158 & 0.91 & $\mathrm{Se} 2-\mathrm{Se} 1 \bullet \bullet \mathrm{N} 1^{\mathrm{v}}$ & 165.3 \\
\hline $\operatorname{Se} 1 \cdot \bullet B r 1^{v i}$ & 3.530 & 0.94 & $\mathrm{C} 1-\mathrm{Se} 1 \cdot \bullet \mathrm{Br} 1^{\mathrm{vi}}$ & 163.2 \\
\hline $\mathrm{Se} 2 \bullet \bullet \cdot \mathrm{Br} 1$ & 3.036 & 0.81 & Se1-Se2 $\bullet \bullet B r 1$ & 174.2 \\
\hline $\mathrm{Se} 2 \cdot \bullet \bullet B r 1^{\mathrm{vii}}$ & 3.289 & 0.88 & $\mathrm{C} 2-\mathrm{Se} 2 \cdot \bullet \cdot \mathrm{Br} 1^{\mathrm{vii}}$ & 177.9 \\
\hline
\end{tabular}


Among the acyclic diselenides, only a few examples of intermolecular ChB interactions with Lewis bases are found, indicating already that these interactions do not play an important role in these highly flexible molecules. The thiazole derivative ${ }^{23}$ (Table 2: FEYBAP) provides an example of relatively long but directional $\mathrm{ChB}$ interaction with the $\mathrm{sp} 2$ nitrogen atom, characterized by a Se $\bullet \bullet N$ distance at $3.342 \AA(R R=0.97)$ and a linear interaction as the Se-Se $\bullet \cdot N$ angle amounts to $171.9^{\circ}$. Note that the Se-Se intramolecular distance $(2.307 \AA)$ is not modified by the interaction and compares with that found in simple alkyldiselenides (2.29-2.31 A). The more rigid, four-membered (HOGBOW, Figure 4) or five-membered (UDELUL, DECYOB) cyclic diselenides shown in Table 2 provide evidence for a directional interaction between the sp2 $\mathrm{O}$ or $\mathrm{N}$ atoms, or the sp $\mathrm{N}$ atom, with the Se-Se motif. As shown in Table 2, the Se•••(O/N) distances are close to van der Waals contacts, indicating again that these intermolecular interactions, albeit present, are not very strong.

Table 2. Structural characteristics of intermolecular ChB

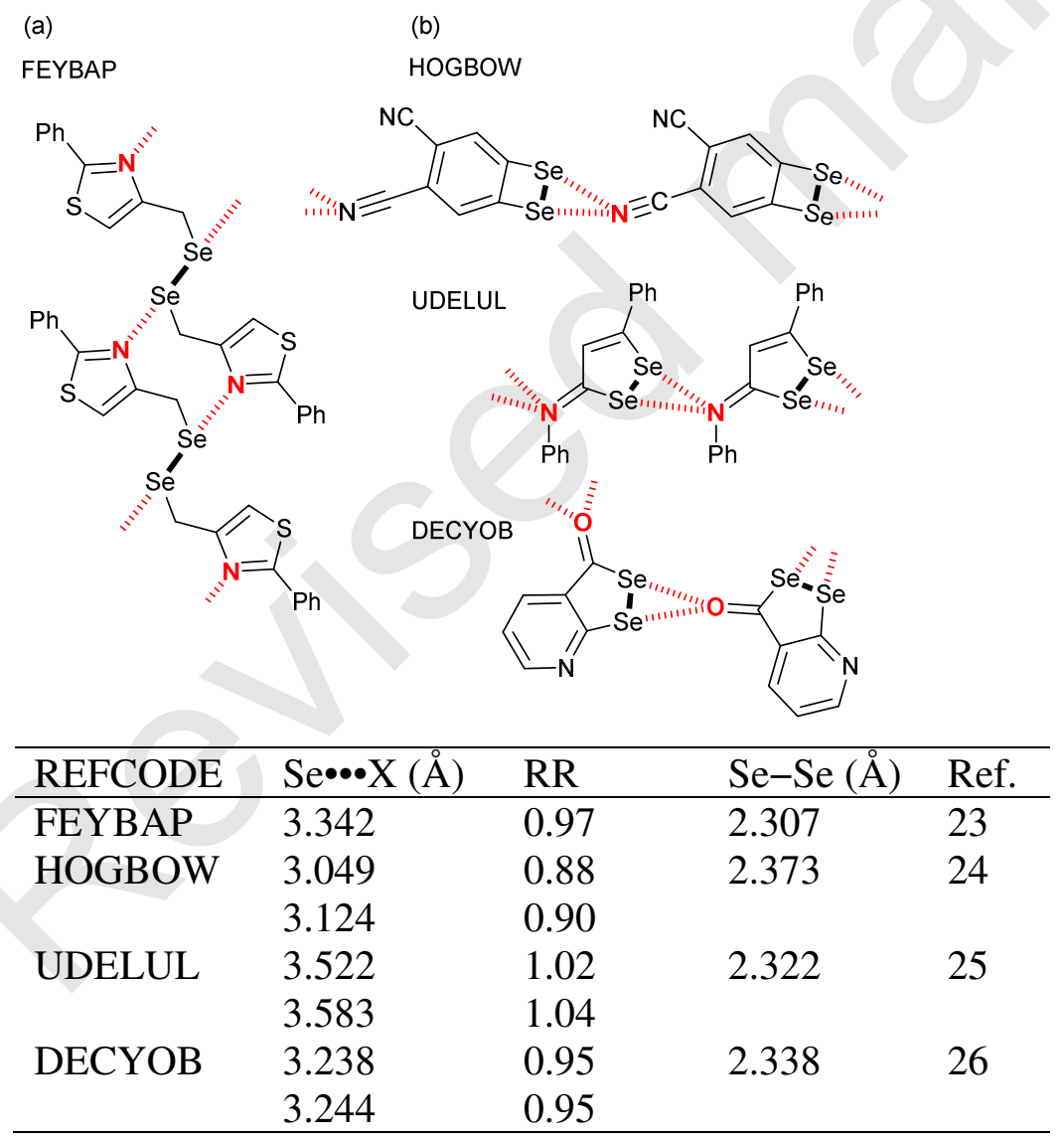




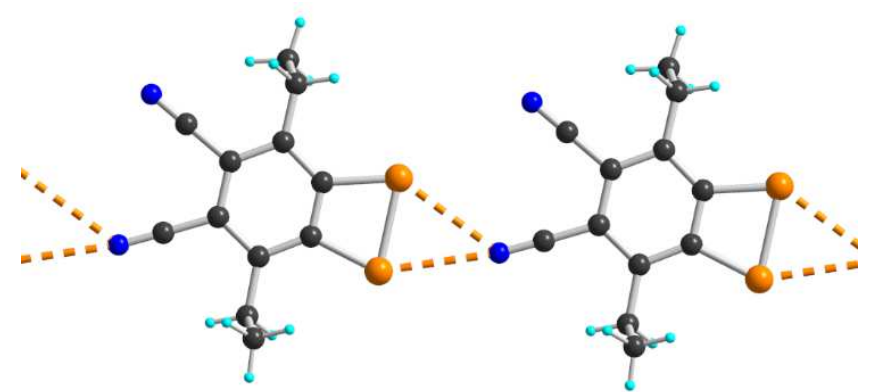

Figure 4. Detail of the $\mathrm{ChB}$ interaction (orange dotted line) in the crystal structure of 2,5diethyl-7,8-diselenabicyclo[4.2.0]octa-1,3,5-triene-3,4-dicarbonitrile (HOGBOW). ${ }^{24}$

\section{Distances}

\subsection{Intramolecular $\mathrm{ChB}$ interactions in diselenides}

At variance with the limited intermolecular $\mathrm{ChB}$ interactions detailed above, intramolecular $\mathrm{ChB}$ interactions in diselenides are recurrent. They have been divided here into three categories, those described as 1,5-interactions, which involve the $\sigma$-holes in the prolongation of the Se-Se bond, those described as 1,4 interactions, which settle in the prolongation of the C-Se bond, and those found in cationic systems whose positive charge activates the $\mathrm{ChB}$ interaction

\subsubsection{1,5 ChB interactions}

Diaryldiselenides with ortho substituents bearing a Lewis base in $\beta$ position (Scheme 1) offer the most beautiful playground for the observation of $\mathrm{ChB}$ interactions in diselenides and four representative examples are shown in Figure 5. As collected in Scheme 1, almost 40 examples are reported in the literature involving sp2 (imine, oxazoline) or sp3 (tertiary amine) nitrogen atom as Lewis base, but also sp2 (carbonyl) and sp3 (ether) oxygen atoms, and even chlorine and bromine. Contact distances are very short, with averaged reduction ratio (RR) around 0.81 , for nitrogen as well as for oxygen-based Lewis bases. Imine-type systems act as stronger ChB acceptors than the tertiary amines, with RR values of $0.78 v s .0 .83$ for the latter. Directionality is also marked with Se-Se•• X angles between 170 and $180^{\circ}$. These amide derivatives are involved in the glutathione peroxidase(GPx)-like catalytic activity of the organoselenium compound ebselen. ${ }^{3,27}$ 
Scheme 1. Diaryl diselenides with ortho substituents favoring $1,5 \mathrm{ChB}$ interactions<smiles>[R]c1ccccc1[Se][Se]c1ccccc1[R]</smiles><smiles>[Y]c1ccccc1[Se][Se]c1ccccc1[Y]</smiles><smiles>[R]C(C)(C)C1=NCCO1</smiles><smiles>CC1=NC(C)(C)CO1</smiles><smiles>BrC1CCOC1</smiles>

BEWLUL

JOWTAQ

JOWXIC<smiles>CC(C)(C)C1=NC(CO)C(c2ccccc2)O1</smiles><smiles>CCC=Nc1ccccc1</smiles><smiles>CC=Nc1ccccc1O</smiles>

CATWEB

REDGAK

REDGUE<smiles>Cc1ccc(N=CC(C)(C)C)cc1</smiles><smiles>CC=NNc1ccc(C)cc1</smiles>

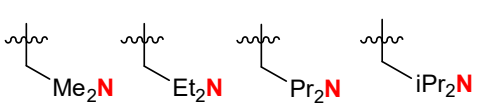<smiles>CCN1CCCCC1</smiles>

VELCOG CIDXUJ<smiles>[AlH2]</smiles>

TIRYUO VAZSOG VUXNAE VUXNIM

inter<smiles>[AlH2]C1OCCO1</smiles><smiles>CC1(C)OCCO1</smiles><smiles>CC(C)(C)CN1CCN2CCN1CC2</smiles>

QUBQEK QUBQAG FUXTEY QIGNAV FUBHAN YUFNOC

$\mathrm{Bu}-\mathrm{S}_{\mathrm{O}=\mathrm{O}}^{\mathrm{n}=\mathrm{O}}$

$$
\text { FUXTAU SIDHOD }
$$

FUXTUO SIDHOD01

FUBHER HIRGIZ

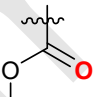<smiles>CN1C(=O)CCC1=O</smiles>

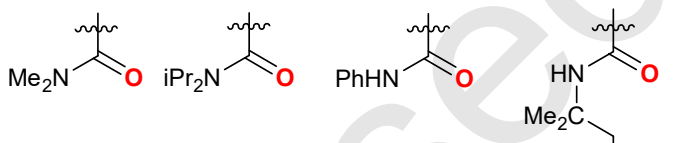

RULROG RULRAS TOMTUL TOMVEX OH PUYPUW<smiles>CCN(CC)CCNC(=O)C(C)NC(=O)CNC(=O)OC</smiles><smiles>C=CNC(=O)C(C)(C)C</smiles> 


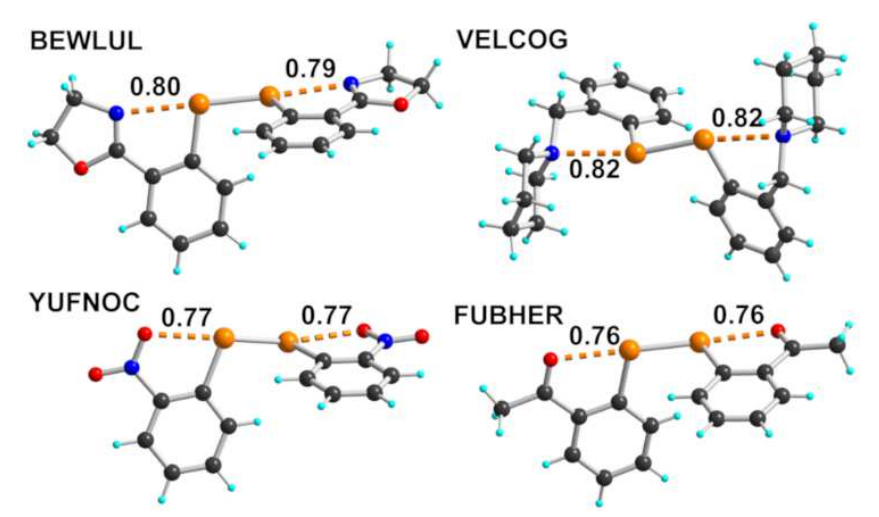

Figure 5. Four examples (with CCDC codes and RR values, see Scheme 1) of intramolecular $\mathrm{ChB}$ interactions in acyclic diselenides.

Table 3. Structural characteristics of $\mathrm{ChB}$ in diaryl diselenides with 1,5 interaction (see Scheme 1).

\begin{tabular}{llllllll}
\hline & & & & & & \\
\end{tabular}




\begin{tabular}{|c|c|c|c|c|c|c|c|}
\hline & VUXNAE & 2.782 & 0.81 & 174.2 & 2.348 & +96.05 & 36 \\
\hline & & 2.988 & 0.87 & 173.3 & & & \\
\hline & VUXNIM & 2.950 & 0.85 & 174.8 & 2.346 & +105.30 & 36 \\
\hline & & 2.943 & 0.85 & 171.5 & & & \\
\hline & VELCOG & 2.822 & 0.82 & 168.9 & 2.355 & -97.17 & 37 \\
\hline & CIDXUJ & 2.813 & 0.81 & 162.6 & 2.346 & +80.93 & 38 \\
\hline & & 2.825 & 0.82 & 166.4 & & & \\
\hline & CIDXET & 2.739 & 0.79 & 171.9 & 2.370 & -114.00 & 38 \\
\hline & & 3.135 & 0.91 & 165.3 & & & \\
\hline $\mathrm{Cl}$ & QUBQEK $^{(\mathrm{b})}$ & 3.537 & 0.97 & 166.4 & 2.313 & -90.13 & 39 \\
\hline & & 3.680 & 1.01 & 162.5 & & & \\
\hline & & 3.679 & 1.01 & 169.8 & 2.314 & -85.07 & \\
\hline & & 3.471 & 0.95 & 173.3 & & & \\
\hline $\mathrm{Br}$ & QUBQAG & 3.673 & 0.98 & 170.0 & 2.309 & +87.59 & 39 \\
\hline & & 3.828 & 1.02 & 168.0 & & & \\
\hline S & FUXTEY & 3.261 & 0.88 & 153.2 & 2.309 & -89.45 & 40 \\
\hline & & 3.237 & 0.87 & 152.3 & & & \\
\hline O sp3 & QIGNAV & 2.940 & 0.86 & 169.3 & 2.318 & -89.50 & 41 \\
\hline & & 3.005 & 0.88 & 169.6 & 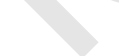 & & \\
\hline & FUBHAN & 2.775 & 0.81 & 176.5 & 2.321 & -90.34 & 42 \\
\hline & & 2.775 & 0.81 & 175.8 & & & \\
\hline O sp2 & YUFNOC & 2.635 & 0.77 & 166.2 & 2.330 & -84.46 & 43 \\
\hline & & 2.628 & 0.77 & 163.5 & & & \\
\hline & FUXTAU & 2.796 & 0.82 & 178.1 & 2.324 & +96.24 & 44 \\
\hline & & 2.784 & 0.81 & 170.0 & & & \\
\hline & FUXTUO & 2.776 & 0.81 & 178.2 & 2.316 & +78.91 & 44 \\
\hline & & 2.758 & 0.81 & 169.8 & & & \\
\hline & SIDHOD $^{(b)}$ & 2.720 & 0.79 & 170.0 & 2.321 & -86.32 & 45 \\
\hline & & 2.751 & 0.80 & 165.7 & & & \\
\hline & & 2.729 & 0.80 & 168.3 & 2.325 & -86.28 & \\
\hline & & 2.725 & 0.80 & 172.2 & & & \\
\hline & SIDHOD01 $1^{\text {b }}$ & 2.744 & 0.80 & 167.8 & 2.335 & +90.51 & 46 \\
\hline & & 2.704 & 0.79 & 175.9 & & & \\
\hline & & 2.731 & 0.80 & 172.4 & 2.335 & -87.81 & \\
\hline & & 2.720 & 0.79 & 175.9 & & & \\
\hline & FUBHER $^{(b)}$ & 2.649 & 0.77 & 173.6 & 2.353 & -82.79 & 42 \\
\hline & & 2.624 & 0.77 & 174.2 & & & \\
\hline & & 2.613 & 0.76 & 174.2 & 2.342 & -77.20 & \\
\hline & & 2.609 & 0.76 & 175.9 & & & \\
\hline & HIRGIZ & 2.684 & 0.78 & 176.0 & 2.329 & -84.57 & 47 \\
\hline & ICEWIY & 2.726 & 0.80 & 170.5 & 2.329 & -81.11 & 48 \\
\hline & & 2.799 & 0.82 & 175.4 & & & \\
\hline Amides: & RULROG & 2.793 & 0.82 & 171.4 & 2.326 & +92.28 & 27 \\
\hline & & 2.852 & 0.83 & 163.7 & & & \\
\hline
\end{tabular}




$\begin{array}{lllllll}\text { RULRAS } & 3.053 & 0.89 & 171.1 & 2.318 & +92.82 & 27 \\ & 3.264 & 0.95 & 169.1 & & & \\ \text { TOMTUL } & 2.854 & 0.83 & 173.7 & 2.326 & +86.19 & 3 \\ \text { TOMVEX } & 2.97 & 0.87 & 173.7 & 2.327 & -91.27 & 3 \\ & 2.720 & 0.79 & 163.4 & & & \\ \text { PUYPUW } & 2.711 & 0.79 & 169.8 & 2.330 & +88.85 & 49 \\ & 2.735 & 0.80 & 171.2 & & & \\ \text { ICEVIX } & 2.729 & 0.80 & 177.2 & 2.328 & +97.42 & 48 \\ \text { ICEVUJ } & 2.739 & 0.80 & 177.2 & 2.334 & -97.37 & 48 \\ \text { ICEWEU } & 2.718 & 0.79 & 169.8 & 2.329 & +87.36 & 48 \\ & 2.665 & 0.78 & 165.7 & & & \\ \text { KAHJIP } & 2.763 & 0.81 & 175.4 & 2.339 & +93.47 & 50\end{array}$

(a) $\delta\left({ }^{\circ}\right)$ is the $\mathrm{C}-\mathrm{Se}-\mathrm{Se}-\mathrm{C}$ torsion angle. ${ }^{(b)}$ Two crystallographically independent molecules

Another interesting feature within these series is the evolution of the Se-Se bond with the strength of the $\mathrm{ChB}$ interaction. The plot of this Se-Se distance vs. RR (Figure 6) shows indeed a clear tendency for a Se-Se bond lengthening associated with the smallest RR values, i.e. the strongest $\mathrm{ChB}$. This evolution confirms the partial charge-transfer character of such strong ChBs since this lengthening is directly correlated with the partial occupancy of the $\sigma^{*} \mathrm{Se}-\mathrm{Se}$ antibonding orbital.

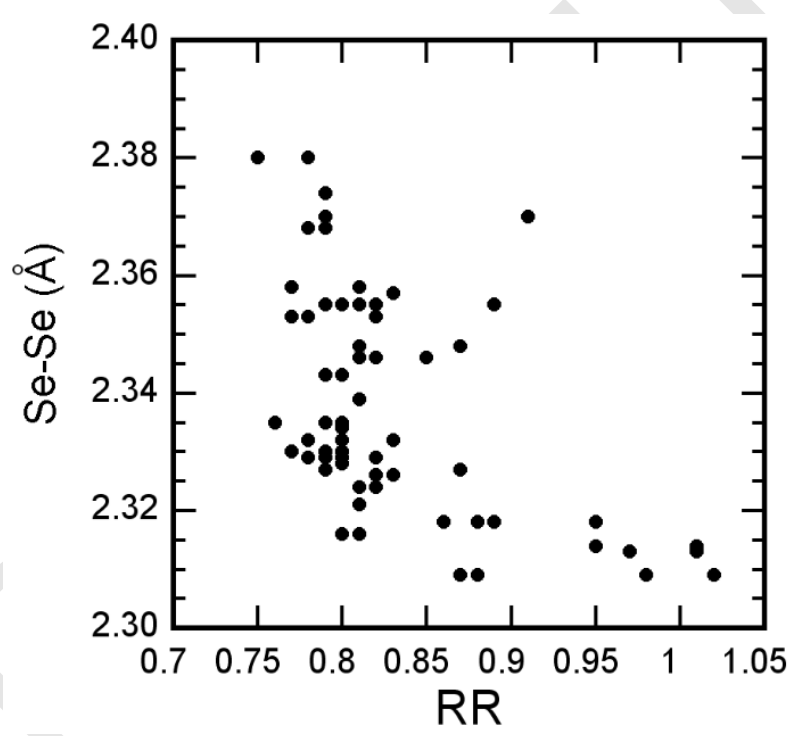

Figure 6. Evolution of the $\mathrm{Se}-\mathrm{Se}$ distance with the reduction ratio associated with the $\mathrm{ChB}$ interaction in the series of diaryl diselenides with 1,5 interaction (See Table 3 and Scheme 1)

The second other large series of diselenides exhibiting 1,5 ChB interactions is found in the naphthalene derivatives collected in Table 4, with two examples shown in Figure 7. As 
observed above, short Se $\bullet \cdot X$ contacts and strong directionality characterize these series. On the other hand, the Se-Se bond lengths (2.32-2.38 $\AA$ ) compare with that reported for the unsubstituted bis( $\alpha$-naphtyl)diselenide (IGIXIH), ${ }^{51}$ where it amounts to $2.355 \AA$. This linear motif in the all-chalcogen derivatives (VOLYUR, EVUMAL, ZONXUV) has been analyzed as extended hypervalent interaction by the $\sigma(4 c-6 e)$ model within the framework of quantum theory of atoms-in-molecules (QTAIM) approach. Investigations of the electronic density characteristics at Bond Critical points (BCP) shows a shared-shell character for the Se••SeR and Se•••SR associated with a partial degree of covalency. ${ }^{52}$

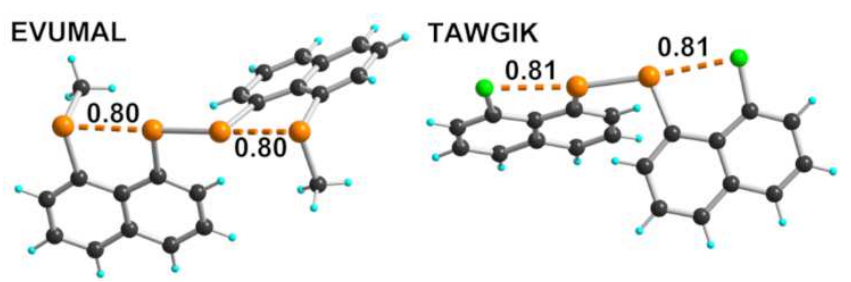

Figure 7. Two examples (with CCDC codes and RR values, see Table 4) of intramolecular ChB interactions in $\alpha$-naphtyl diselenides

Table 4. Structural characteristics of $\mathrm{ChB}$ in dinaphthyl diselenides with 1,5 interaction

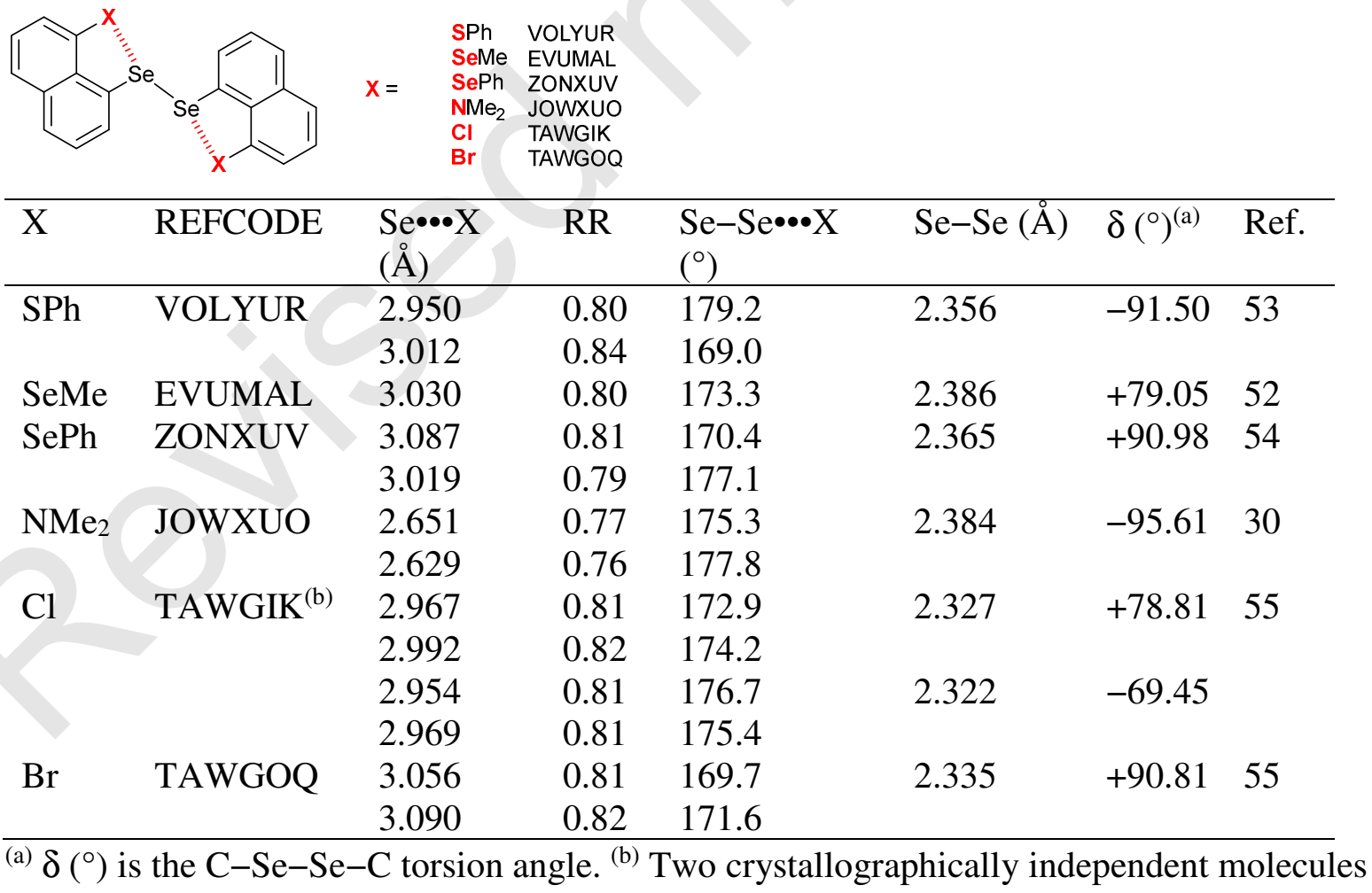


Dipyridyldiselenides provide another series of 1,5 interactions involving as Lewis base the carbonyl oxygen atom of acids, esters and amides (Figure $8 \&$ Table 5) interacting with acyclic diselenides. Note that besides the 1,5 interaction, the pyridinic nitrogen atom also enters in a

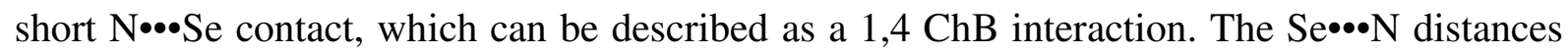
amount to $84 \%$ of the van der Waals contact distance. These 1,4 interactions, most probably contribute to the planarization of these systems (see below Part 3.2.2.), at variance with the other derivatives described above where the absence of this extra interaction leaves the rotation around the $\mathrm{Se}-\mathrm{Se}$ bond with a $\mathrm{C}-\mathrm{Se}-\mathrm{Se}-\mathrm{C}$ torsion angle $\delta$ around $\pm 90^{\circ}$ as shown in Tables 3 and 4.
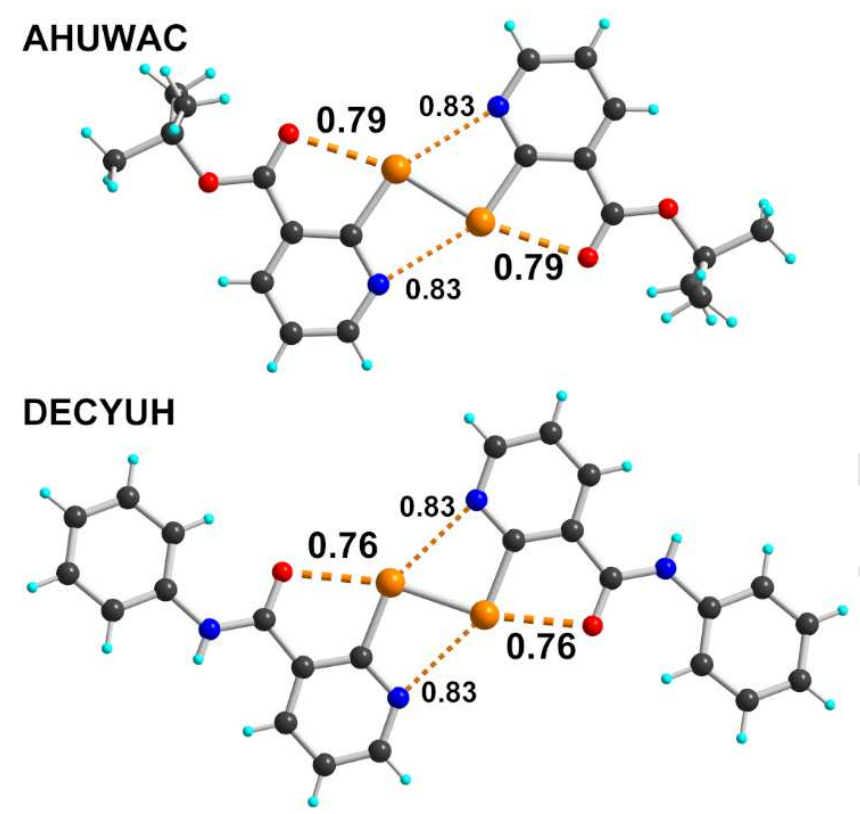

Figure 8. Two examples (with CCDC codes and RR values, see Table 5) of intramolecular ChB interactions in $\alpha$-pyridyl diselenides. Se $\bullet O$ interactions as bold dotted lines, Se $\bullet \bullet N$ interactions as thin dotted lines. 
Table 5. Structural characteristics of $\mathrm{ChB}$ in dipyridyldiselenides with 1,5 and 1,4 interactions<smiles></smiles>

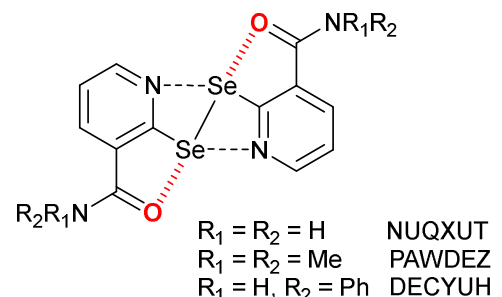

\begin{tabular}{|c|c|c|c|c|c|c|c|c|}
\hline REFCODE & $\begin{array}{l}\mathrm{Se} \bullet \bullet \cdot \mathrm{O} \\
(\AA)\end{array}$ & RR & $\begin{array}{l}\mathrm{Se}-\mathrm{Se} \bullet \bullet \cdot \mathrm{O} \\
\left({ }^{\circ}\right)\end{array}$ & $\begin{array}{l}\mathrm{Se}-\mathrm{Se} \\
(\AA)\end{array}$ & $\begin{array}{l}\text { Se•••N } \\
(\AA)\end{array}$ & RR & $\delta\left({ }^{\circ}\right)^{(\mathrm{a})}$ & Ref \\
\hline AHUVUV & 2.703 & 0.79 & 166.7 & 2.388 & 2.874 & 0.83 & +180 & 56 \\
\hline MUTWOP & 2.659 & 0.78 & 167.1 & 2.383 & 2.898 & 0.84 & -180 & 57 \\
\hline AHUWAC & 2.710 & 0.79 & 165.8 & 2.379 & 2.874 & 0.83 & +180 & 56 \\
\hline \multirow[t]{2}{*}{ NUQXUT $^{(b)}$} & 2.671 & 0.78 & 166.4 & 2.388 & 2.875 & 0.83 & -180 & 58 \\
\hline & 2.638 & & 166.3 & 2.389 & 2.866 & 0.83 & +180 & \\
\hline PAWDEZ & 2.944 & 0.86 & 163.4 & 2.355 & 2.926 & 0.85 & -180 & 59 \\
\hline DECYUH & 2.608 & 0.76 & 166.8 & 2.392 & 2.867 & 0.83 & -180 & 26 \\
\hline
\end{tabular}

(a) $\delta\left(^{\circ}\right)$ is the $\mathrm{C}-\mathrm{Se}-\mathrm{Se}-\mathrm{C}$ torsion angle. ${ }^{(b)}$ Two crystallographically independent molecules

The last series to be described here involves the cyclic diselenides based on the $(1,2)$ diselenole core (Table 6). Compounds based on the diselenolodiselenole core (DOKXEI, CALZEX) were particularly investigated as organic semiconductors. ${ }^{60,61}$ Indeed, the ChB interaction induced by the thienyl substituents favors a planarization of the molecules, at variance with the phenyl derivatives which exhibit a rotation of $53^{\circ}$. In the naphtho $(1,8-$ cd)(1,2)diselenole derivatives (Table 6), an extremely strong ChB interaction is observed (Figure 9), particularly with sp2 iminic nitrogen atoms (HATBOV, HATBUB) with reduction ratio (RR) down to 0.63 . Note that the shortest $\mathrm{ChB}$ is indeed associated with a notable lengthening of the Se-Se bond when compared with the unsubstituted derivatives. These naphthalene series were investigated by Mugesh et $a l$. as reagents for the deiodination of thyroid hormones and their decarboxylated metabolites, iodothyronamines. ${ }^{62}$ 
Table 6. Structural characteristics of $\mathrm{ChB}$ in (1,2)-diselenoles.

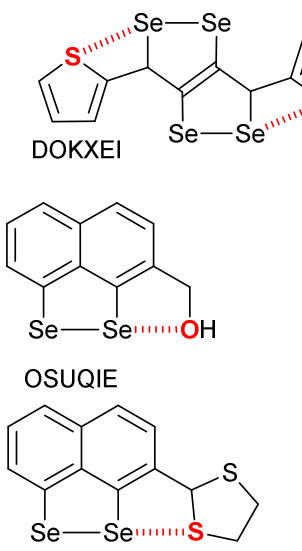

LOJMEE
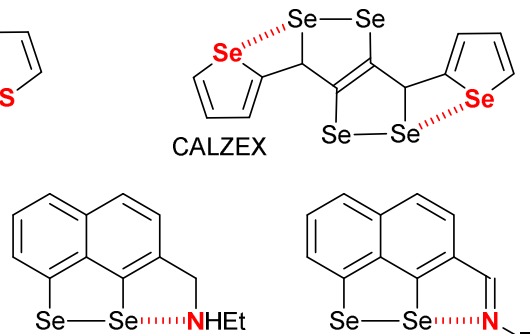

HATCEM<smiles>[R]N[C@@H]1[SeH]c2cccc3cccc1c23</smiles>

OSUQUK

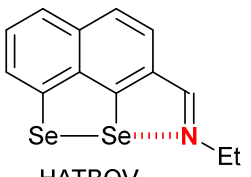

HATBOV

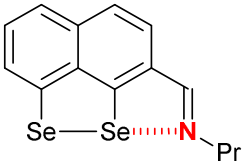

HATBUB

\begin{tabular}{lllllll}
\hline $\mathrm{X}$ & $\mathrm{REFCODE}$ & $\mathrm{Se} \bullet \boldsymbol{X}(\AA)$ & $\mathrm{RR}$ & $\mathrm{Se}-\mathrm{Se} \bullet{ }^{\mathrm{X}}\left({ }^{\circ}\right)$ & $\mathrm{Se}-\mathrm{Se}$ & $\mathrm{Ref}$.
\end{tabular}

\section{$(\AA)$}

Diphenyl

DOKXAE

$-$

2.345

60

diselenolodiselenole

S

DOKXEI $\quad 3.036$

$0.82 \quad 172.1$

2.328

60

$\mathrm{Se}$

CALZEX $\quad 3.076$

$0.81 \quad 174.2$

2.329

61

\section{Unsubstituted}

ZZZBKSOI

2.364

63

Naphtodiselenole

O sp3

OSUQIE

2.818

$0.82 \quad 161.4$

2.348

62

S sp3

LOJMEE

3.090

$\begin{array}{ll}0.84 & 163.9\end{array}$

$2.357 \quad 64$

$\mathrm{N}$ sp3

HATCEM $^{(a)}$

2.560

$0.74 \quad 166.0$

2.426

65

2.542

$0.74 \quad 165.5$

2.416

OSUQOK

2.563

$0.74 \quad 167.0$

2.402

62

$\mathrm{N}$ sp2

$\begin{array}{llllll}\text { HATBOV } & 2.183 & 0.63 & 166.2 & 2.533 & 65 \\ \text { HATBUB } & 2.287 & 0.66 & 166.9 & 2.470 & 65\end{array}$

(a) Two crystallographically independent molecules 

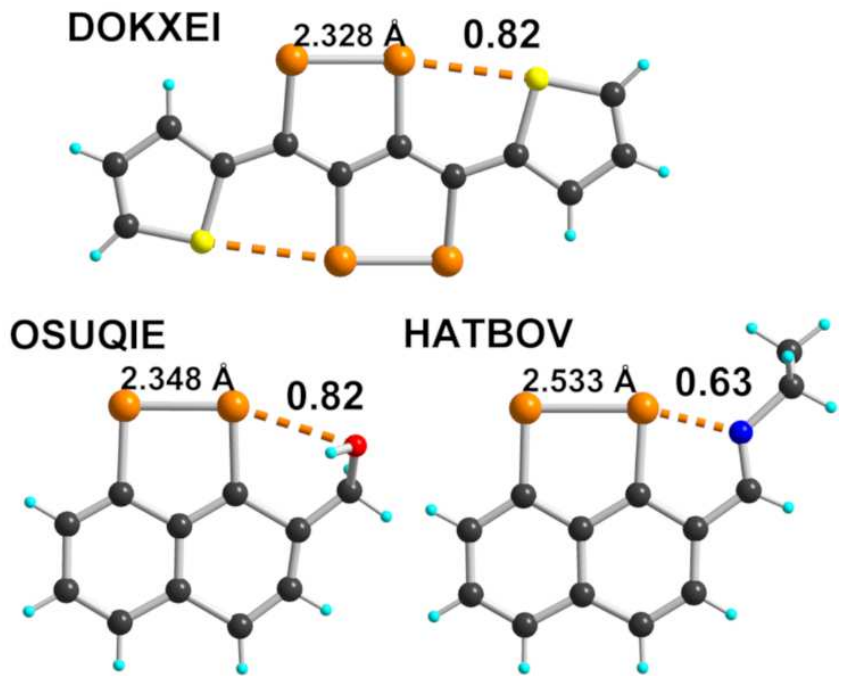

Figure 9. Three examples (with CCDC codes and RR values) of intramolecular ChB interactions in diselenole systems. See Table 6 for details.

\subsubsection{1,4 ChB interactions}

We have seen above that the $\sigma$-hole interactions with diselenides can develop either in the prolongation of the $\mathrm{Se}-\mathrm{Se}$ bond, but also in the prolongation of the $\mathrm{C}-\mathrm{Se}$ bonds, involving a diffuse positive area in between the two Se atoms, able to interact with Lewis bases through 1,4 $\mathrm{ChB}$ interactions. A striking consequence is then a full planarization of these acyclic diselenides $\left(\delta= \pm 180^{\circ}\right)$, which are known otherwise to exhibit $\mathrm{C}-\mathrm{Se}-\mathrm{Se}-\mathrm{C}$ torsion angles around $\pm 90^{\circ}$. As shown in Figure 10 and Table 7, some dipyridyl diselenides provide a few examples of a fully planarized system with short Se••N intramolecular contacts.

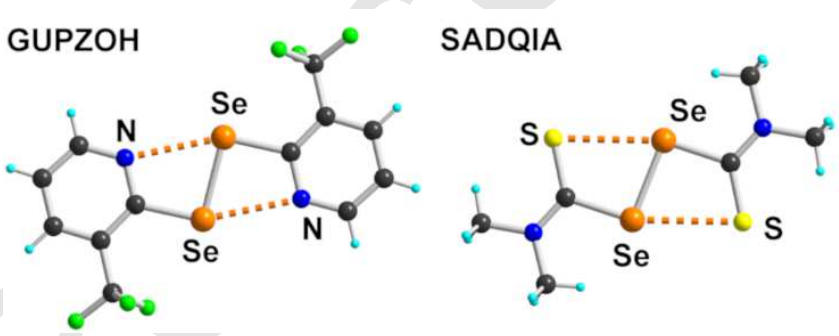

Figure 10. Two examples of intramolecular 1,4 ChB interactions. See Tables 7 and 8 for details. 
Table 7. Structural characteristics of $1,4 \mathrm{ChB}$ interactions in dipyridyl diselenides.

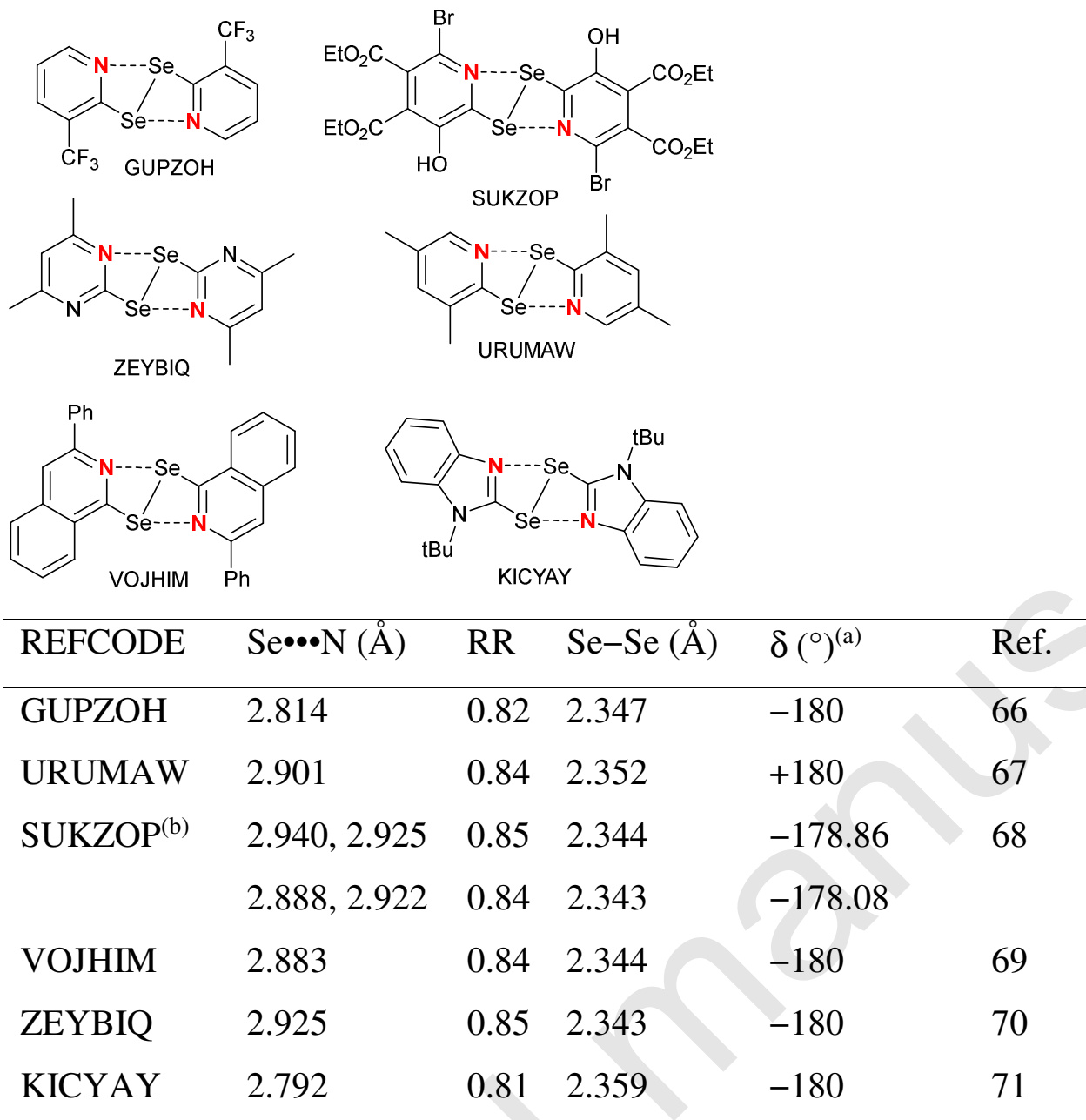

(a) $\delta\left(^{\circ}\right)$ is the $\mathrm{C}-\mathrm{Se}-\mathrm{Se}-\mathrm{C}$ torsion angle. ${ }^{(\mathrm{b})}$ Two crystallographically independent molecules

Another interesting series where these $1,4 \mathrm{ChB}$ interactions are at work, is found in diselenides interacting with sulfur atoms as thiones or thiolates (or selenolates), as collected in Table 8. Note that the negative charge beard by the Lewis base (in PAMKIX, PAMKET and PAMKOD) does not lead to a stronger $\mathrm{ChB}$ interaction when compared with the neutral compound (SADQIA, Figure 10). We will see in the following that the opposite situation where the diselenide bears a positive charge will strongly enhance the $\mathrm{ChB}$ interaction. 
Table 8. Structural characteristics of $1,4 \mathrm{ChB}$ interactions with sulfur-based Lewis bases.

\begin{tabular}{|c|c|c|c|c|c|}
\hline $\begin{array}{l}R=\text { Me SADQIA } \\
R=i P r \text { VETBUS }\end{array}$ & $\begin{array}{l}\mathrm{C}^{+}=\mathrm{PH}_{4} \mathrm{As}^{+} \\
\mathrm{C}^{+}=\mathrm{nBu}_{4} \mathrm{~N}^{+}\end{array}$ & $\mathrm{C}^{+}=\mathrm{P}$ & PAMKOD & & \\
\hline REFCODE & $\mathrm{Se} \bullet \bullet \mathrm{S}(\mathrm{Se})(\AA)$ & RR & $\operatorname{Se}-\operatorname{Se}(\AA)$ & $\delta\left(^{\circ}\right)^{(\mathrm{a})}$ & Ref. \\
\hline SADQIA & 3.070 & 0.83 & 2.358 & -180 & 72 \\
\hline VETBUS & 3.082 & 0.83 & 2.343 & +180 & 73 \\
\hline PAMKIX & 3.130 & 0.85 & 2.325 & -180 & 74 \\
\hline PAMKET & 3.199 & 0.93 & 2.337 & +180 & 74 \\
\hline PAMKOD & 3.194 & 0.84 & 2.328 & -180 & 74 \\
\hline
\end{tabular}

(a) $\delta\left(^{\circ}\right)$ is the $\mathrm{C}-\mathrm{Se}-\mathrm{Se}-\mathrm{C}$ torsion angle.

\subsection{Charge activation of $\mathrm{ChB}$}

Charge activation in halogen-bonded systems is a well-established process, which is observed either in cationic XB donors or using anionic Lewis bases as XB acceptors. Similarly, several cationic diselenides have been reported and structurally characterized, demonstrating indeed a notable activation of the $\sigma$-holes, both along the $\mathrm{Se}-\mathrm{Se}$ bond and along the $\mathrm{C}-\mathrm{Se}$ bonds in between the two Se atoms. We will first describe the purely cationic systems and then those found in radical cations obtained upon one-electron oxidation of 1,2-diselenole systems.

\subsubsection{Charge activation in ionic systems}

Most examples are found in series of bis(imidazolium), bis(formamidinium) or bis(anilinium) dications linked by a diselenide bridge, interacting with halide $\left(\mathrm{Cl}^{-}, \mathrm{Br}^{-}, \mathrm{I}^{-}\right)$or polyhalide $\left(\mathrm{I}_{3}^{-}\right.$, $\mathrm{IBr}_{2}{ }^{-}$) counterions acting as ChB acceptors. They are collected in Table 9 with a few examples shown in Figure 11. The most striking feature is in some instances the very short $\mathrm{ChB}$ interaction, with reduction ratio down to 0.83 , illustrating the effectiveness of the charge activation, despite the competition with numerous hydrogen bond interactions which also take place around the halide anions. The shortest interactions involve the $\sigma$-holes in the prolongation of the $\mathrm{Se}-\mathrm{Se}$ bond while interaction with the $\sigma$-holes in the prolongation of the $\mathrm{C}-\mathrm{Se}$ bond are most often close to van der Waals contact distances $(0.9<\mathrm{RR}<1)$ but still with strong linearity. Note also the significant lengthening of the intramolecular Se-Se bond, in the range 2.34-2.43 $\AA$, at variance with "naked" diselenides where it amounts to 2.32-2.36 ̊. These compounds 
were investigated in details as they derive from selenium analogs of anti-thyroid drugs, through inhibition of lactoperoxidase (LPO)-catalyzed iodination of L-tyrosine. ${ }^{75,76,77}$

Table 9. Structural characteristics of $\mathrm{ChB}$ in cationic diselenides with $\mathrm{ChB}$ interactions with halides or polyhalides.
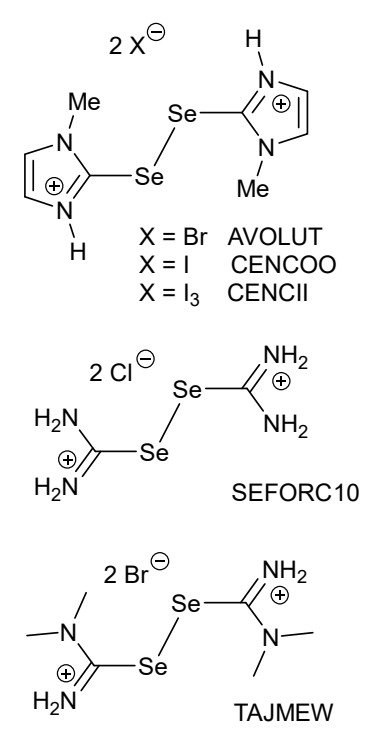
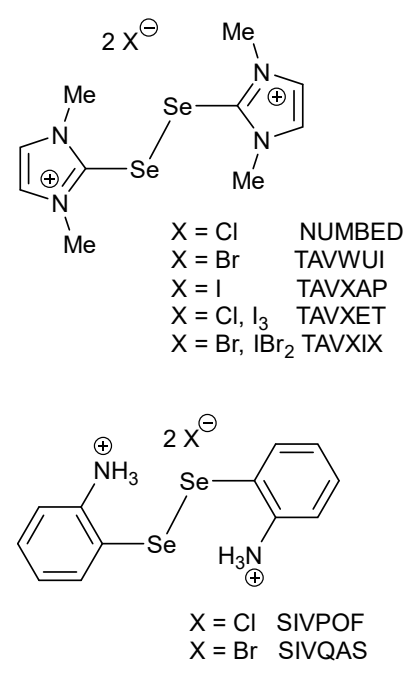

\begin{tabular}{|c|c|c|c|c|c|}
\hline REFCODE & Se•••X $(\AA)$ & RR & $\operatorname{Se}(\mathrm{C})-\mathrm{Se} \bullet \bullet X\left(^{\circ}\right)$ & $\operatorname{Se}-\operatorname{Se}(\AA)$ & Ref. \\
\hline \multirow[t]{3}{*}{ AVOLUT } & $3.315(\mathrm{Br})$ & 0.88 & 165.7 & 2.361 & 78 \\
\hline & $3.505(\mathrm{Br})$ & 0.93 & 171.6 & & \\
\hline & $3.762(\mathrm{Br})$ & 1.00 & 166.9 & & \\
\hline \multirow[t]{4}{*}{ CENCOO } & 3.415 (I) & 0.88 & 168.4 & 2.386 & 79 \\
\hline & 3.708 (I) & 0.95 & 163.5 & & \\
\hline & 3.661 (I) & 0.94 & 163.9 & & \\
\hline & $3.664(\mathrm{I})$ & 0.94 & 160.5 & & \\
\hline \multirow[t]{5}{*}{ CENCII $^{\text {(a) }}$} & $3.616(\mathrm{I})$ & 0.93 & 174.6 & 2.382 & 79 \\
\hline & 3.644 (I) & 0.94 & 174.0 & 2.364 & \\
\hline & 3.702 (I) & 0.95 & 156.3 & & \\
\hline & 3.759 (I) & 0.97 & 167.6 & & \\
\hline & 3.799 (I) & 0.98 & 162.9 & & \\
\hline \multirow[t]{3}{*}{ NUMBED } & $3.029(\mathrm{Cl})$ & 0.83 & 177.0 & 2.397 & 80 \\
\hline & $3.083(\mathrm{Cl})$ & 0.84 & 163.9 & & \\
\hline & $3.413(\mathrm{Cl})$ & 0.88 & 164.7 & & \\
\hline \multirow[t]{2}{*}{ TAVWUI } & $3.166(\mathrm{Br})$ & 0.84 & 177.0 & 2.409 & 81 \\
\hline & $3.242(\mathrm{Br})$ & 0.86 & 164.1 & & \\
\hline
\end{tabular}




\begin{tabular}{llllll} 
& $3.505(\mathrm{Br})$ & 0.93 & 164.9 & & \\
TAVXAP & $3.330(\mathrm{I})$ & 0.86 & 176.0 & 2.434 & 81 \\
& $3.410(\mathrm{I})$ & 0.88 & 165.8 & & \\
& $3.626(\mathrm{I})$ & 0.93 & 165.0 & 2.379 & 82 \\
SEFORC10 & $3.187(\mathrm{Cl})$ & 0.87 & 169.4 & & \\
& $3.514(\mathrm{Cl})$ & 0.96 & 164.3 & 2.385 & 83 \\
TAJMEW & $3.056(\mathrm{Br})$ & 0.81 & 168.8 & & \\
& $3.639(\mathrm{Br})$ & 0.97 & 153.4 & & \\
& $3.764(\mathrm{Br})$ & 1.00 & 164.0 & 2.343 & 20 \\
SIVPOF & $3.530(\mathrm{Cl})$ & 0.97 & 153.1 & & \\
& $3.423(\mathrm{Cl})$ & 0.94 & 171.3 & 2.347 & 20 \\
SIVQAS & $3.682(\mathrm{Br})$ & 0.98 & 153.3 & & \\
& $3.570(\mathrm{Br})$ & 0.95 & 173.4 & & \\
\hline
\end{tabular}

(a) Two crystallographically independent molecules

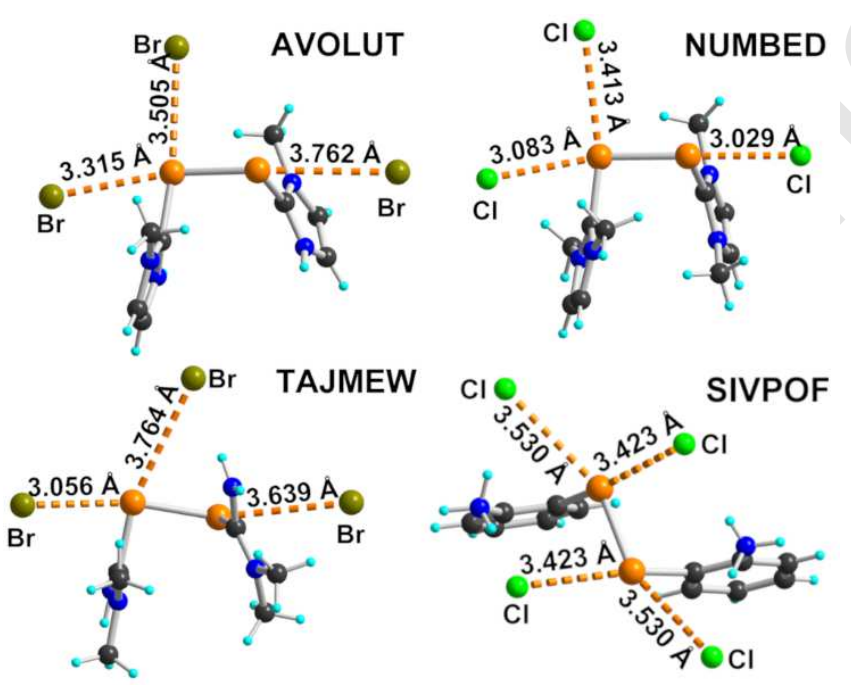

Figure 11. Representative examples of $\mathrm{ChB}$ interactions of dicationic diselenides. See Table 9 for details.

\subsubsection{Charge activation in cation radical salts}

Molecular conductors and metals are most often obtained from the partial oxidation of an electron-rich donor molecule (for example tetrathiafulvalene, abbreviated as TTF) toward mixed valence salts formulated as (TTF) $)_{2} \mathrm{X}$, where $\mathrm{X}$ is a monovalent counter ion. The stacking of the partially oxidized molecules leads to the formation of a partially filled (3/4-filled) 
conduction band and the associated metallic behavior. ${ }^{84}$ While halogen bonding in such molecular conductors has been purposely sought by introducing iodine substituents directly on a TTF core, ${ }^{85}$ chalcogen bonding interactions were observed mostly on cyclic $(1,2)$-diselenoles fused with naphthalene or perylene moieties (Scheme 2, molecules A-E). Their cation radical salts have been obtained from the chemical or electrochemical (electrocrystallization) oxidation. The HOMO of such electron-rich molecules is essentially concentrated on the diselenole ring, with large coefficients on the two selenium atoms. ${ }^{86}$ As a consequence, upon oxidation, the radical cation is strongly localized on the selenium atoms, which thus can efficiently interact with the negatively charged counterions, be they simple halides $\left(\mathrm{Cl}^{-}\right.$, $\left.\mathrm{SCN}^{-}\right),{ }^{87,88}$ halometallates $\left(\mathrm{CuBr}_{2}{ }^{-89}, \mathrm{Hg}_{2} \mathrm{Br}_{6}{ }^{2-},{ }^{90} \mathrm{Hg}_{2} \mathrm{I}_{6}{ }^{2-}\right),{ }^{91}$ cyanometallates ${ }^{92}$ or organic radical anions derived from TCNQ (tetracyanoquinodimethane) derivatives. ${ }^{93,94}$

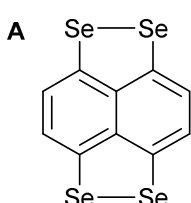

(A)Cl VAMZEO

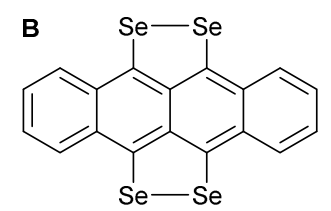

B)SCN TSETCN

$(\mathrm{B})_{2} \mathrm{Cl}$ TSETCl10

(B) $\left(\mathrm{CuBr}_{2}\right) \quad$ BUCKUF

(B) $)_{3}\left(\mathrm{Hg}_{2} \mathrm{Br}_{6}\right)$ BUWBOK

(B) ${ }_{2}\left(\mathrm{Hg}_{2} \mathrm{I}_{6}\right)$ CINPAQ

(B)(BTDA) PEFGUC01

(B)(BTDA) PEFGEM

(B) $)_{2}\left[\mathrm{Fe}(\mathrm{CN})_{5}(\mathrm{NO})\right]$

LUQNUG

Electron acceptors

$\mathrm{Me}_{2} \mathrm{TCNQ}$

NC $\mathrm{CN}$<smiles></smiles>

BTDA-TCNQ

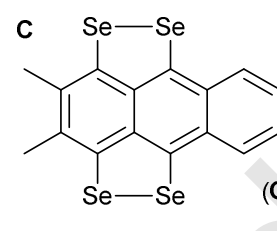

$(\mathrm{C})_{2}\left(\mathrm{Me}_{2} \mathrm{TCNQ}\right)$ JOBMUI

D $\mathrm{Se}$-Se

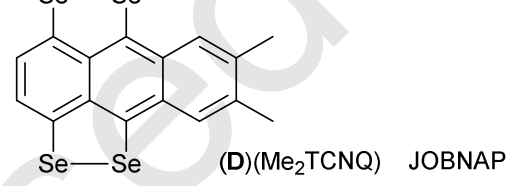

E $\mathrm{Se}-\mathrm{Se}$

Se-se

(D) $\left(\mathrm{Me}_{2} \mathrm{TCNQ}\right)$ JOBNAP

Scheme 2. Molecular structures of diselenides acting as electron donors and CCDC codes of the corresponding cation radical salts.

With the smallest chloride counter ion, two salts were described involving the naphthalene and the tetracene derivatives $\mathbf{A}$ and $\mathbf{B}$ respectively, in VAMZEO ${ }^{95}$ and TSETCL10. ${ }^{87}$ As shown in Figure 12, the less sterically hindered $\mathbf{A}$ derivative in the 1:1 salt $(\mathbf{A}) \mathrm{Cl}$ allows for a strong Se $\bullet \mathrm{Cl}^{-} \mathrm{ChB}$ interaction $(\mathrm{RR}=0.85)$, involving the $\sigma$-hole in the prolongation of the $\mathrm{Se}-\mathrm{Se}$ bond, with additional, weaker interactions involving the $\sigma$-hole along the $\mathrm{C}-$ Se bonds $(\mathrm{RR}=$ 
0.95). The situation is rather different with the more hindered tetracene derivative $\mathbf{B}$ in its mixed-valence 2:1 salt $(\mathbf{B})_{2} \mathrm{Cl}$, where only the latter $\sigma$-holes are involved in even stronger $\mathrm{ChB}$ $(\mathrm{RR}=0.80-0.83)$. These two examples show that $\mathrm{ChB}$ donors can be used in anion recognition processes, with here chloride anions in a $\mu_{4}$ or $\mu_{6}$ coordination pattern. We will see below other examples with selenocyanates acting as $\mathrm{ChB}$ donors (See Part 3) toward halides.

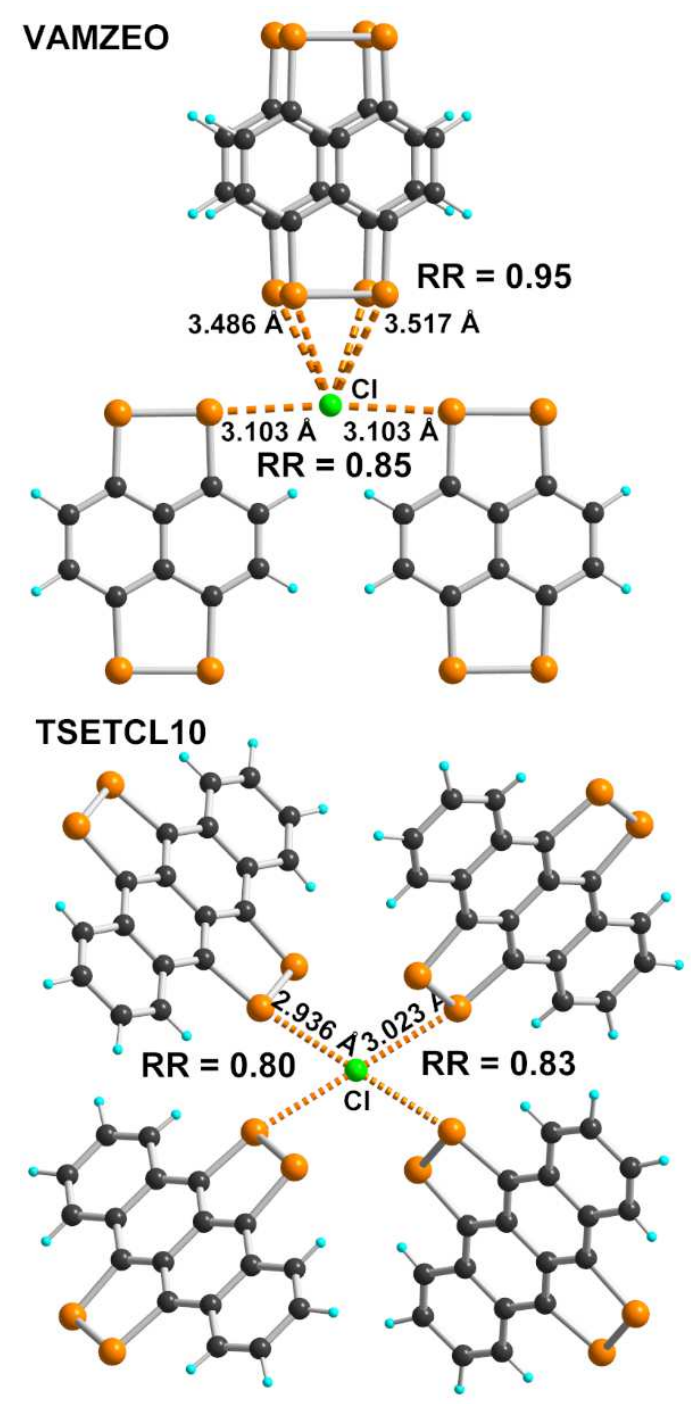

Figure 12. Detail of the chloride anion environment in the two cation radical salts $(\mathbf{A}) \mathrm{Cl}$ (VAMZEO) and (B) $)_{2} \mathrm{Cl}$ (TSETCL10).

Another very interesting series is found in the two salts obtained from the tetracene derivative B and the organic electron acceptor BDTA-TCNQ (BDTA-TCNQ: 4,8-bis(dicyanomethylene)4H,8H-benzo[1,2-c:4,5-c']bis[1,2,5]thiadiazole) in PEFCUC01 and PEFGEM. ${ }^{94}$ Both compounds have same 1:1 stoichiometry, with added PhCl molecule in PEFGEM. They exhibit very similar ChB motifs, with the nitrile of BDTA-TCNQ acting as CHB acceptor toward both 
Se atoms of each diselenole ring (Figure 13). The main difference lies in the actual degree of charge transfer $(\rho)$ between the electron donor, molecule $\mathbf{B}$, and the electron acceptor, BDTATCNQ. Based on the intramolecular bond lengths in BDTA-TCNQ and the conductivity behavior, this charge transfer is estimated to be close to $0(\rho=0.2 \pm 0.3)$ in the insulating charge-transfer complex PEFGEM, while it is estimated to be close to $1(\rho=0.9 \pm 0.2)$ in the conducting charge-transfer salt PEFCUC01. This striking difference is clearly seen in the characteristics of the $\mathrm{ChB}$ interaction. Indeed, the charged system exhibits stronger $\mathrm{ChB}$ (RR = 0.89 ) than the neutral one ( $\mathrm{RR}=0.92-0.93)$, a convincing evidence of this charge activation process, already observed in comparable halogen-bonded charge transfer salts. ${ }^{96}$

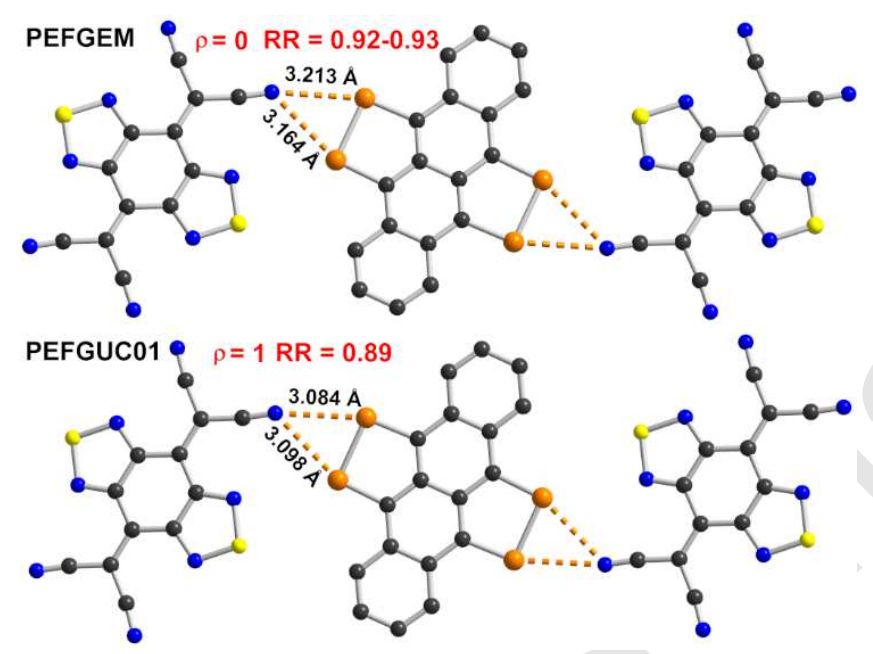

Figure 13. Detail of the $\mathrm{ChB}$ in insulating (B)(BDTA-TCNQ)•PhCl (PEFGGEM) and conducting (B)(BDTA-TCNQ) (PEFGUC01).

\section{ChB interactions in selenocyanates}

Organic selenocyanates $\mathrm{R}-\mathrm{SeCN}$ constitutes a smaller group of around 30 reported crystal structures, but where $\mathrm{ChB}$ interactions proved to be present in all examples. In most diselenides described above, the preferred interaction site was, when sterically possible, the $\sigma$-hole located in the prolongation of the Se-Se bond. Organic selenocyanates are expected to exhibit a stronger dissymmetry, with a strongly electron withdrawing group nitrile group on one side, and accordingly a stronger $\sigma$-hole in the prolongation of the NC-Se bond. This dissymmetry might be very useful if one wants to use such $\mathrm{ChB}$ donors, for example in crystal engineering 
strategies, since the presence of one single (or predominant) $\sigma$-hole brings a strong element of predictability.

\subsection{Intramolecular interactions in selenocyanates}

A few examples of intramolecular ChB involving selenocyanates (Table 10) are found as in methyl 2-selenocyanatobenzoate (AHEQIN), ${ }^{97}$ phenacyl selenocyanate (FAGGAV) ${ }^{98}$ and 8(dimethylamino)-1-naphthyl selenocyanate (GUYJUV). ${ }^{99}$ They can be compared with analogous situations encountered above in diselenides. For example, the characteristic 1,5interaction found here in AHEQUI or HEPPIE parallels those reported in the numerous diaryldiselenides collected in Table 3 . The interaction is actually stronger $(\mathrm{RR}=0.75-0.77)$ here than those reported in Table 3 for comparable diselenides interacting with sp2 oxygen atoms $\left(\mathrm{RR}_{\mathrm{aver}}=0.80\right)$, a first indication of the stronger $\mathrm{ChB}$ donor ability of selenocyanates. It is also indicated by the naphthalene derivative GIYJUV with $\mathrm{RR}=0.71$, while the corresponding diselenide (JOWXUO in Table 4) exhibits two Se $\bullet \bullet N$ short contacts with RR values at $0.76-0.77$. Besides the strongest intramolecular $\mathrm{ChB}$ in the prolongation of the $\mathrm{NC}-\mathrm{Se}$ bond, one also often observes in these compounds a secondary, intermolecular $\mathrm{ChB}$ involving the second $\sigma$-hole on selenium, toward the nitrogen atom of the nitrile moiety of a neighboring molecule with RR values in the range $0.93-0.95$ and a notable directionality. This is illustrated for example here in the structure adopted by the 2-nitrophenylselenocyanate (HEPPIE) in Figure 14.

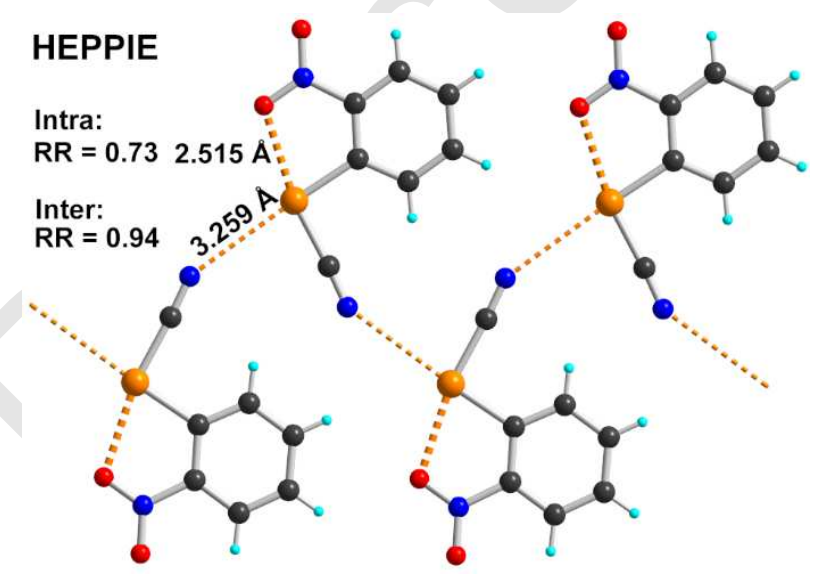

Figure 14. Intra- and intermolecular $\mathrm{ChB}$ in 2-nitrobenzeneselenocyanate. 
Table 10. Structural characteristics of selenocyanates exhibiting intramolecular ChB.<smiles>COC(=O)c1ccccc1[Se]O</smiles>

AHEQIN

$\mathrm{Me}_{2} \mathrm{~N} \cdots \cdots \cdots \mathrm{Se}-\mathrm{CN}$<smiles>CN(C)[Se]C#N</smiles>

GIYJUV<smiles>[AlH2]=[W]=[W]</smiles><smiles>N#C[Se]1CC(=O)c2ccccc21</smiles>

FAGGAV

\begin{tabular}{lllll}
\hline REFCODE & $\mathrm{Se} \bullet \bullet \mathrm{X}(\AA)$ & $\mathrm{RR}$ & $\mathrm{C}-\mathrm{Se} \bullet \bullet \mathrm{Y}\left({ }^{\circ}\right)$ & Ref \\
\hline AHEQIN & $2.561(\mathrm{X}=\mathrm{O})$ & 0.75 & 170.3 & 97 \\
& $3.271(\mathrm{X}=\mathrm{N})$ & 0.95 & 167.3 & \\
FAGGAV & $2.723(\mathrm{X}=\mathrm{O})$ & 0.80 & 152.0 & 98 \\
& - & - & - & \\
HEPPIE & $2.514(\mathrm{X}=\mathrm{O})$ & 0.73 & 169.8 & 100 \\
& $3.259(\mathrm{X}=\mathrm{N})$ & 0.94 & 175.5 & \\
HEPPIE01 & $2.525(\mathrm{X}=\mathrm{O})$ & 0.74 & 170.1 & 100 \\
\multirow{2}{*}{ GIYJUV } & $3.222(\mathrm{X}=\mathrm{N})$ & 0.93 & 178.9 & \\
& $2.456(\mathrm{X}=\mathrm{NMe})$ & 0.71 & 172.6 & 99 \\
& - & - & - &
\end{tabular}

\subsection{Intermolecular interactions in selenocyanates}

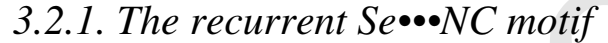

The vast majority of structurally characterized selenocyanates (Table 11) is characterized by recurrent intermolecular Se•• NC interactions which lead to the formation of infinite chain-like motifs $\bullet \bullet \mathrm{Se}(\mathrm{R})-\mathrm{CN} \bullet \bullet \mathrm{Se}(\mathrm{R})-\mathrm{CN} \bullet \bullet$. They are found in many aromatic as well as benzylic selenocyanates, and are characterized with strong and highly directional $\mathrm{ChB}$ interactions. We believe that such one-dimensional systems are also stabilized by cooperativity, as indeed theoretically demonstrated in model systems such as $\mathrm{Se}(\mathrm{CN})_{2} \cdot{ }^{101}$ One representative example is shown in Figure 15 (benzylselenocyanate, CIGGOO) and structural characteristics of reported structures are collected in Table 11. It should be stressed also that in most structures, besides the shortest $\mathrm{Se} \bullet \bullet \mathrm{NC}$ contact in the prolongation of the $\mathrm{NC}-\mathrm{Se}$ bond, a secondary $\mathrm{ChB}$ interaction also takes place with the other selenium $\sigma$-hole, in an inversion centered motif involving a neighboring $\bullet \bullet \mathrm{Se}(\mathrm{R})-\mathrm{CN} \bullet \bullet \mathrm{Se}(\mathrm{R})-\mathrm{CN} \bullet \bullet$ chain (see Figure 15 for an illustration). 
Table 11. $\mathrm{ChB}$ characteristics of $\bullet \bullet \mathrm{Se}(\mathrm{R})-\mathrm{CN} \bullet \bullet \mathrm{Se}(\mathrm{R})-\mathrm{CN} \bullet \bullet$ chains formed by selenocyanates.
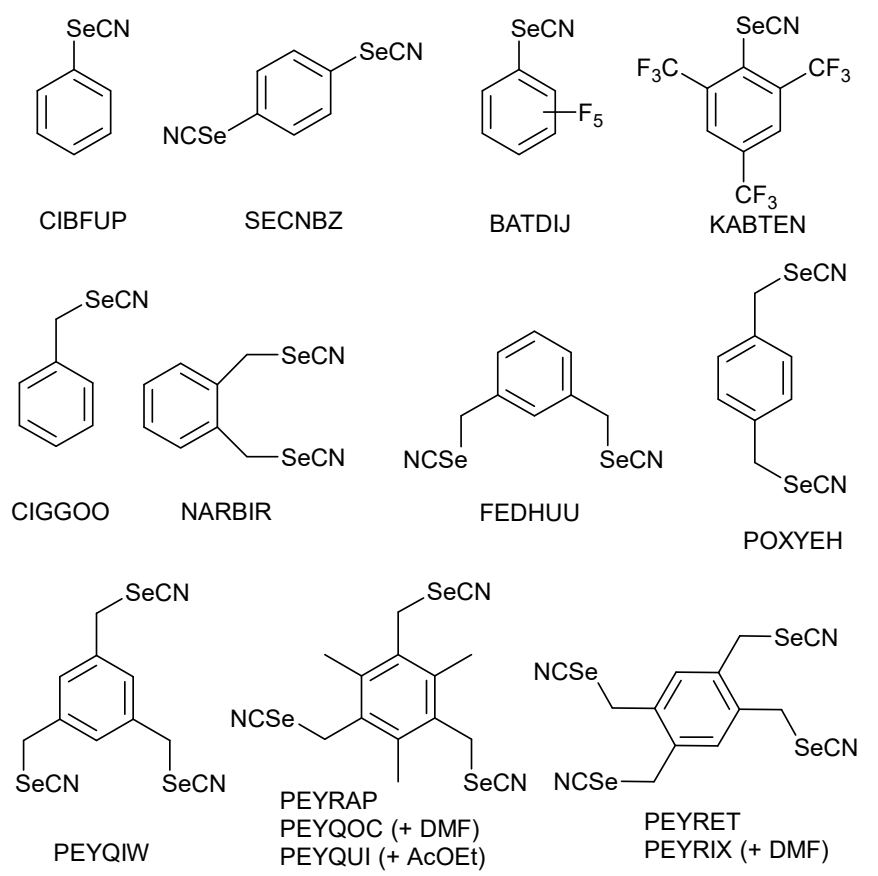

\begin{tabular}{|c|c|c|c|c|}
\hline REFCODE & Se•••N $(\AA)$ & RR & $\mathrm{C}-\mathrm{Se} \bullet \bullet \mathrm{N}\left({ }^{\circ}\right)$ & Ref. \\
\hline \multirow[t]{2}{*}{ CIBFUP } & $3.023^{(a)}$ & 0.88 & 172.9 & 102 \\
\hline & 3.065 & 0.89 & 166.1 & \\
\hline SECNBZ & 3.06 & 0.89 & 162.32 & 103 \\
\hline \multirow[t]{2}{*}{ BATDIJ } & $2.958^{(a)}$ & 0.86 & 175.6 & 104 \\
\hline & 2.964 & 0.86 & 172.1 & \\
\hline \multirow[t]{2}{*}{ KABTEN } & $2.883^{(b)}$ & 0.84 & 173.1 & 105 \\
\hline & 2.968 & 0.86 & 166.4 & \\
\hline CIGGOO & 2.997 & 0.87 & 167.1 & 106 \\
\hline \multirow[t]{2}{*}{ NARBIR } & 2.985 & 0.86 & 172.9 & 107 \\
\hline & 2.969 & 0.86 & 172.6 & \\
\hline \multirow[t]{4}{*}{ FEDHUU } & $2.965^{\text {(a) }}$ & 0.86 & 175.9 & 108 \\
\hline & 3.017 & 0.87 & 175.7 & \\
\hline & 3.010 & 0.87 & 172.9 & \\
\hline & 3.015 & 0.87 & 174.1 & \\
\hline \multirow[t]{2}{*}{ POXYEH } & $2.997^{\text {(a) }}$ & 0.86 & 174.4 & 109 \\
\hline & 3.022 & 0.88 & 171.8 & \\
\hline \multirow[t]{3}{*}{ PEYQIW } & 3.023 & 0.88 & 168.5 & 110 \\
\hline & 3.011 & 0.87 & 169.3 & \\
\hline & 3.243 & 0.94 & 134.8 & \\
\hline \multirow[t]{4}{*}{ PEYRAP } & 2.986 & 0.86 & 171.4 & 110 \\
\hline & 3.292 & 0.95 & 155.8 & \\
\hline & 3.188 & 0.92 & 177.4 & \\
\hline & 3.336 & 0.97 & 155.8 & \\
\hline PEYQOC $^{(a)}$ & 2.960 & 0.86 & 175.4 & 110 \\
\hline
\end{tabular}




\begin{tabular}{lllll} 
& 2.964 & 0.86 & 176.1 & \\
& 2.972 & 0.86 & 173.8 & \\
PEYQUI $^{(b)}$ & 3.174 & 0.92 & 177.0 & 110 \\
& 2.965 & 0.86 & 174.9 & \\
PEYRET & 3.085 & 0.89 & 164.0 & 110 \\
& 3.202 & 0.93 & 167.6 & \\
GOHMEW & 3.370 & 0.98 & 170.0 & 111 \\
ZUTTAL & 3.199 & 0.93 & 145.7 & 112 \\
\hline
\end{tabular}

(a) Se $\bullet \bullet$ interaction with DMF not reported here. (b) Se••O interaction with AcOEt not reported here

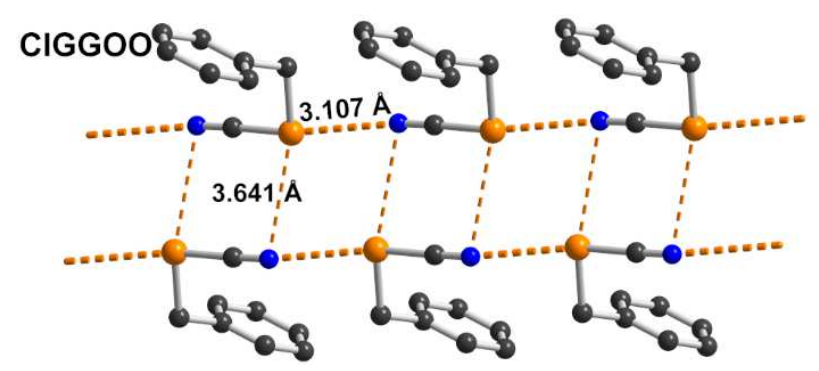

Figure 15. Illustration of the $\bullet \bullet \mathrm{Se}(\mathrm{R})-\mathrm{CN} \bullet \bullet \mathrm{Se}(\mathrm{R})-\mathrm{CN} \bullet \bullet$ chains in benzylselenocyanate.

\subsubsection{Other inter(intra)molecular interactions}

In a few examples, the nitrogen atom of the selenocyanate group acting as $\mathrm{ChB}$ acceptor is actually displaced by other groups of stronger Lewis base character (Table 12). This is particularly observed in selenocyanates bearing a pyridinic nitrogen atom (WERYAT), a selenomethyl moiety (YUNSIK) or a nitro group (CIGGEE, HEPPUQ). As shown in Figure 16, besides the strongest $\mathrm{Se} \bullet \bullet \mathrm{O}$ or Se $\bullet^{\mathrm{N}} \mathrm{ChB}$ interaction in the prolongation of the $\mathrm{NC}-\mathrm{Se}$ bond, we again note also the secondary Se••NC interaction involving the second $\sigma$-hole of the selenium atom. 
Table 12. ChB characteristics of selenocyanates with intermolecular interactions involving other groups than the nitrile.

\begin{tabular}{lllll} 
REFCODE & $\mathrm{Se} \bullet \bullet \times(\AA)$ & $\mathrm{RR}$ & $\mathrm{C}-\mathrm{Se} \bullet \bullet\left(^{\circ}\right)$ & Ref. \\
\hline CIGGEE & $3.005(\mathrm{O})$ & 0.88 & 166.2 & 106 \\
& $3.174(\mathrm{O})$ & 0.93 & 163.9 & \\
HEPPUQ & $3.289(\mathrm{O})$ & 0.96 & 166.8 & 100 \\
& $3.333(\mathrm{NC})$ & 0.97 & 173.3 & \\
YUNSIK & $3.467(\mathrm{X}=\mathrm{Se})$ & 0.91 & 163.4 & 109 \\
& $3.215(\mathrm{X}=\mathrm{N})$ & 0.93 & 166.7 & \\
WERYAT & $2.843(\mathrm{~N})$ & 0.82 & 174.0 & 113 \\
& $3.387(\mathrm{NC})$ & 0.98 & 172.3 & \\
\hline
\end{tabular}

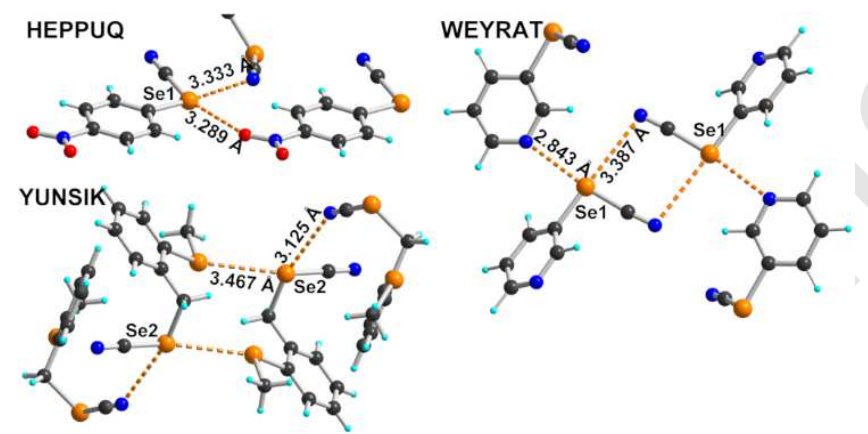

Figure 16. Detail of the selenium environment in three examples of selenocyanates interacting with nitro (HEPPUQ), selenomethyl (WEYRAT) groups or pyridinyl nitrogen atom (YUNSIK).

\subsection{Selenocyanate co-crystals with neutral Lewis bases}

The ChB donor ability of organic selenocyanates observed above in Sections 3.1. and 3.2., either inter or intramolecularly, opens now the possibility for co-crystal formation, associating mono-or poly(selenocyanate) derivatives with other molecules potentially acting as $\mathrm{ChB}$ acceptors. For example, recrystallization of the ortho-bis(selenocyanatomethyl)benzene or the 1,2,4,5-tetrakis(selenocyanatomethyl)benzene in the presence of DMF afforded the mono- and bis DMF adducts respectively, SIZROL and PEYRIX, with short Se••O ChB interactions. As 
shown in Figure 17, they are characterized by a pincer motif where two neighboring SeCN groups actually chelate the oxygen atom of DMF. Another interesting feature of these two structures is the relative orientation of the two neighboring SeCN groups, anti in SIZROL but cis in PEYRIX which exhibits even shorter Se••O distances and a more directional interaction. Electrostatic surface potential calculations have demonstrated the efficiency of this chelating ortho-bis(selenocyanatomethyl) motif, ${ }^{114}$ with $\mathrm{V}_{\mathrm{s}, \max }$ values reaching $50 \mathrm{kcal} \mathrm{mol}^{-1}$, to be compared with the simplest benzyl selenocyanate $\left(36.4 \mathrm{kcal} \mathrm{mol}^{-1}\right)$ or the reference halogen bond donor $\mathrm{F}_{5} \mathrm{C}_{6}-\mathrm{I}\left(35.7 \mathrm{kcal} \mathrm{mol}^{-1}\right)$ in the same conditions. We will see below in Part 3.4 that this chelating ability can be used to also efficiently interact with halide anions.

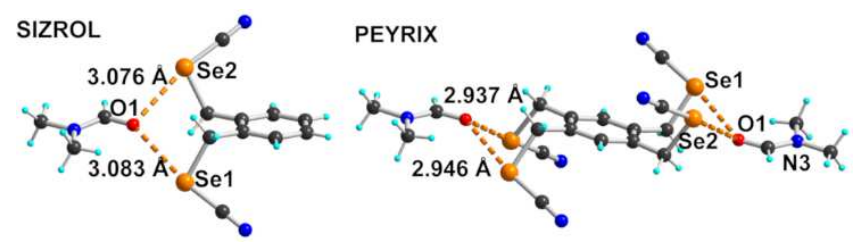

Figure 17. Detail of the $\mathrm{ChB}$ interaction in the chelating systems

On the other hand, the analogous para or meta derivatives were shown to co-crystallize with ditopic Lewis bases such as 4,4'-bipyridine, affording respectively the one-dimensional systems FEDJEG and FEDJAC (Table 13). These two examples demonstrate that the use of the selenocyanate moiety, by enhancing one $\sigma$-hole over the other, allows indeed to recover a degree of predictability comparable to that of halogen bonding. Other Lewis bases such as tetramethylpyrazine, benzoquinone and para-dinitrobenzene were also co-crystallized with the more complex 1,3,5-trimethyl-2,4,6-tris(selenocyanatomethyl)benzene. Three closely related structures were obtained where $\mathrm{Se} \bullet \bullet \mathrm{N}_{\mathrm{Pz}}$ and $\mathrm{Se} \bullet \bullet \mathrm{O} \mathrm{ChB}$ interactions take place, beside additional "classical" Se•••NC short contacts. ${ }^{115}$ 
Table 13. ChB characteristics of selenocyanate adducts with neutral Lewis bases.

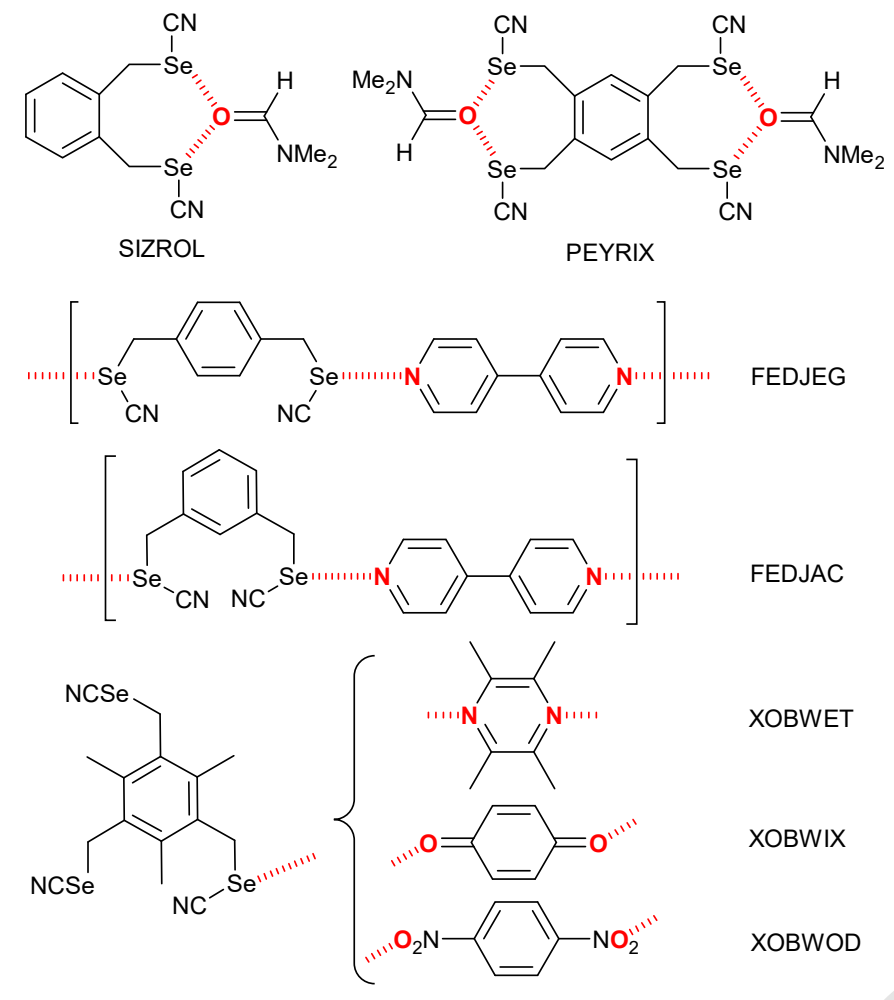

\begin{tabular}{lllll}
\hline Compound & Se••X $(\AA)$ & RR & C-Se••X $\left(^{\circ}\right)$ & Ref. \\
\hline SIZROL $(\mathrm{X}=\mathrm{O})$ & 3.083 & 0.90 & 168.9 & 114 \\
& 3.076 & 0.90 & 168.4 & \\
PEYRIX $(\mathrm{X}=\mathrm{O})$ & 2.946 & 0.86 & 171.9 & 110 \\
& 2.937 & 0.86 & 175.2 & \\
FEDJEG $\left(\mathrm{X}=\mathrm{N}_{\mathrm{Py}}\right)$ & 2.897 & 0.84 & 176.7 & 116 \\
FEDJAC $\left(\mathrm{X}=\mathrm{N}_{\mathrm{Py}}\right)$ & 2.830 & 0.82 & 177.2 & 116 \\
XOBWET $\left(\mathrm{X}=\mathrm{N}_{\mathrm{Pz}}\right)$ & 3.171 & 0.92 & 172.6 & 115 \\
XOBWIX $(\mathrm{X}=\mathrm{O})$ & 2.966 & 0.87 & 170.7 & 115 \\
XOBWOD $(\mathrm{X}=\mathrm{O})$ & 3.231 & 0.94 & 161.9 & 115 \\
\hline
\end{tabular}

\subsection{Selenocyanate adducts with halides}

Using halide anions as $\mathrm{ChB}$ acceptors toward such selenocyanate $\mathrm{ChB}$ donors was a natural evolution, in the continuation of the earlier report of interaction between diselenocyanate (NCSe) $)_{2}$ and $\mathrm{PhNH}_{3}{ }^{+}, \mathrm{Br}^{-}$(see Part 2.4) and this has been first evaluated with the parasubstituted 1,4-bis(selenocyanatomethyl)benzene, co-crystallized with $\mathrm{Bu}_{4} \mathrm{NCl}, \mathrm{Bu}_{4} \mathrm{NBr}$ and Bu 4 NI. As shown in Figure 17 structures with either $\mu_{1}$ or $\mu_{2}$ coordinated halide anions are 
observed in GIHCOS and GIHGIQ respectively. Changes in the ${ }^{13} \mathrm{C}$ and ${ }^{77} \mathrm{Se}$ chemical shifts via NMR spectroscopy showed how halide ion recognition influences the local electronic environment of the selenium atoms in solution. ${ }^{117}$
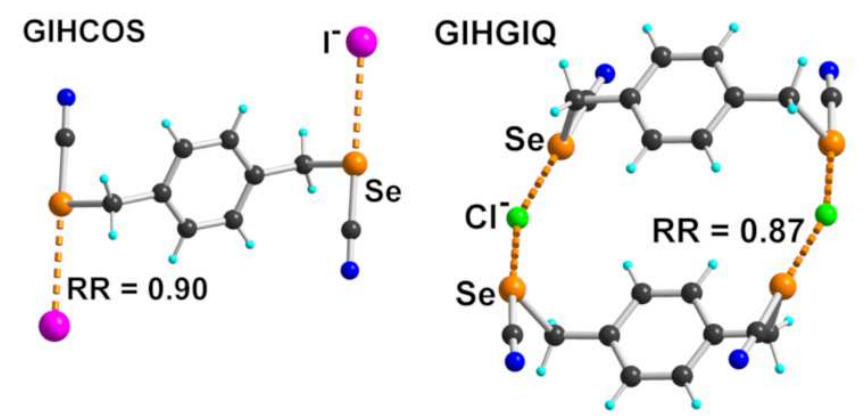

Figure 17. Detail of the ChB interactions around halides with 1,4bis(selenocyanatomethyl)benzene as $\mathrm{ChB}$ donor.

As mentioned above in section 3.3, the chelating interaction with the oxygen atom of DMF found in SIZROL and PEYRIX let us infer that similar structures could be obtained upon association of such ortho bis(selenocyanatomethyl) benzenes with anionic Lewis bases such as halides $\left(\mathrm{Cl}^{-}, \mathrm{Br}^{-}, \mathrm{I}^{-}\right)$. This has been realized with the 1,2-bis(selenocyanatomethyl)benzene as well as with the 1,2,4,5-tetrakis (selenocyanatomethyl)benzene. As shown in Figure 18, not only chelated $\mu_{2}-\mathrm{X}^{-}$structures are found as in SIZRIF, but also $\mu_{4}-\mathrm{X}^{-}$motifs as shown in SIZSIJ or SIZSOM. In the latter, the geometry around the halide anion was found to be intermediate between the tetrahedron and the so-called seesaw $\left(\mathrm{C}_{2 \mathrm{v}}\right)$ model geometries, the latter being built from an octahedron with two vacant vertices. These compounds illustrate the concept of chargeinverted coordination chemistry of $\mathrm{ML}_{\mathrm{n}}$ species, where the metal is actually replaced by the halide anion and the ligands by $\mathrm{ChB}$ donors, as also discussed in XB systems. ${ }^{18,119}$ 
Table $14 \mathrm{ChB}$ characteristics of selenocyanate adducts with halides anions.

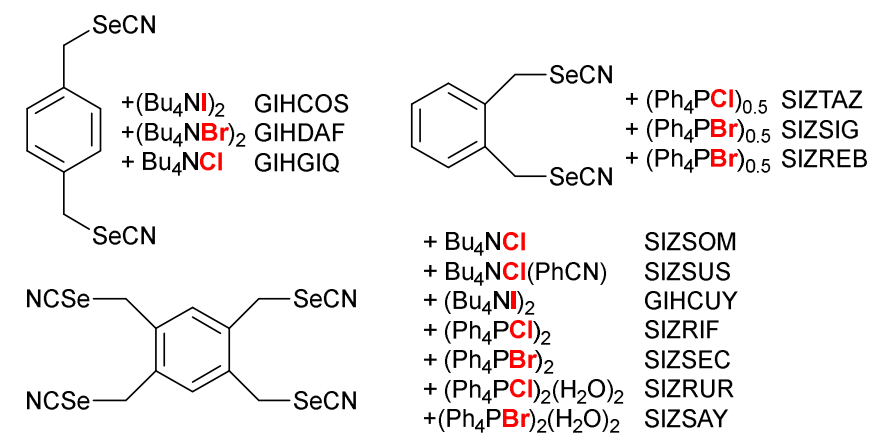

\begin{tabular}{llllll}
\hline Compound & $\mathrm{X}^{-}$ & $\mathrm{Se} \bullet \mathrm{X}^{-}$ & $\mathrm{RR}$ & $\mathrm{C}-\mathrm{Se} \bullet \bullet \mathrm{X}^{-}$ & $\mathrm{Ref}$.
\end{tabular}

(̊)

$\left(^{\circ}\right)$

\begin{tabular}{|c|c|c|c|c|c|}
\hline GIHCOS & $\mu_{1-I^{-}}$ & 3.506 & 0.90 & 174.98 & 117 \\
\hline GIHDAF & $\mu_{1}-\mathrm{Br}^{-}$ & 3.249 & 0.87 & 174.35 & 117 \\
\hline GIHGIQ & $\mu_{2}-\mathrm{Cl}^{-}$ & 3.191 & 0.87 & 174.3 & 117 \\
\hline \multirow[t]{4}{*}{ SIZTAZ } & $\mu_{4}-\mathrm{Cl}^{-}$ & 3.188 & 0.86 & 172.6 & 114 \\
\hline & & 3.166 & 0.85 & 174.9 & \\
\hline & & 3.220 & 0.87 & 179.2 & \\
\hline & & 3.473 & 0.94 & 167.7 & \\
\hline \multirow[t]{4}{*}{ SIZSIG } & $\mu_{4}-\mathrm{Br}^{-}$ & 3.343 & 0.87 & 176.5 & 114 \\
\hline & & 3.186 & 0.82 & 175.4 & \\
\hline & & 3.346 & 0.87 & 171.9 & \\
\hline & & 3.459 & 0.93 & 172.6 & \\
\hline \multirow[t]{4}{*}{ SIZREB } & $\mu_{4}-\mathrm{Br}^{-}$ & 3.363 & 0.87 & 177.5 & 114 \\
\hline & & 3.225 & 0.83 & 174.9 & \\
\hline & & 3.358 & 0.87 & 173.6 & \\
\hline & & 3.552 & 0.92 & 172.9 & \\
\hline \multirow[t]{4}{*}{ SIZSOM } & $\mu_{4}-\mathrm{Cl}^{-}$ & 3.176 & 0.86 & 173.9 & 114 \\
\hline & & 3.162 & 0.85 & 171.2 & \\
\hline & & 3.220 & 0.87 & 174.7 & \\
\hline & & 3.202 & 0.86 & (a) & \\
\hline \multirow[t]{4}{*}{ SIZSUS } & $\mu_{4}-\mathrm{Cl}^{-}$ & 3.154 & 0.85 & 169.9 & 114 \\
\hline & & 3.140 & 0.85 & (a) & \\
\hline & & 3.092 & 0.83 & 173.0 & \\
\hline & & 3.244 & 0.87 & 169.7 & \\
\hline GIHCUY & $\mu_{2-I^{-}}$ & 3.451 & 0.89 & 171.9 & 117 \\
\hline
\end{tabular}




\begin{tabular}{llllll} 
& & 3.511 & 0.90 & 170.8 & \\
SIZRIF & $\mu_{2}-\mathrm{Cl}^{-}$ & 3.132 & 0.84 & 173.3 & 114 \\
& & 3.207 & 0.86 & 173.9 & \\
SIZSEC & $\mu_{2}-\mathrm{Br}^{-}$ & 3.230 & 0.84 & 176.8 & 114 \\
& & 3.250 & 0.84 & 174.6 & \\
SIZRUR & $\mu_{2}-\mathrm{Cl}^{-}$ & 3.104 & 0.85 & 179.4 & 114 \\
& & 3.356 & 0.92 & 172.3 & \\
SIZSAY & $\mu_{2}-\mathrm{Br}^{-}$ & 3.250 & 0.87 & 177.6 & 114 \\
& & 3.454 & 0.92 & 172.8 & \\
\hline
\end{tabular}
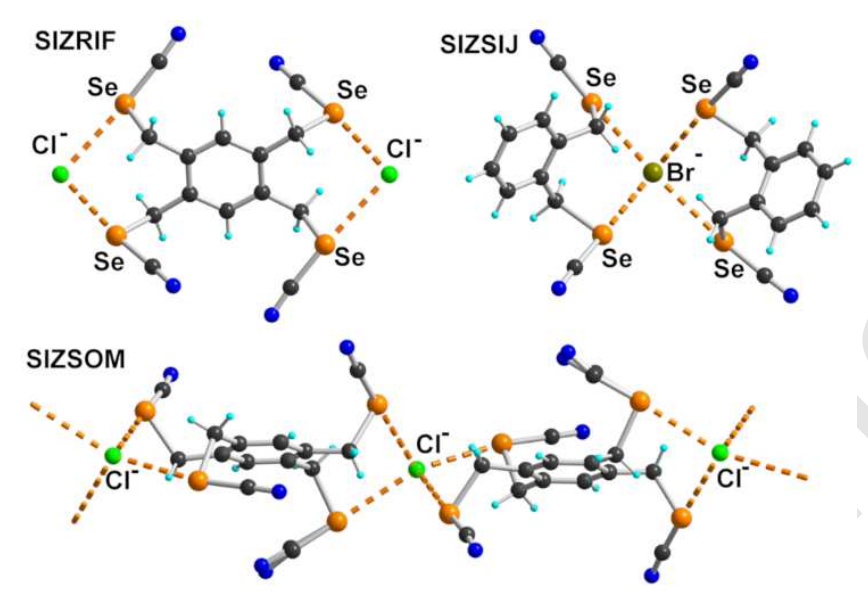

Figure 18. Details of the $\mathrm{ChB}$ interactions around halides with 1,2bis(selenocyanatomethyl)benzene and 1,2,4,5 tetrakis(selenocyanatomethyl)benzene as ChB donors.

\section{Conclusions and perspectives}

This comprehensive search on the crystal structures of organic diselenides with the $\mathrm{C}-\mathrm{Se}-\mathrm{Se}-\mathrm{C}$ motif (> 300 in CSD) has shown that in the absence of specific Lewis-basic substituents and steric constraints, intermolecular interactions were often characterized by a complex set of Se•••Se intermolecular contacts at distances close to the van der Waals contact distance $(2 x$ $1.90=3.80 \AA$ ). On the other hand, a restricted set of more hundred compounds exhibit very specific, short and highly directional interactions between the Se-Se moiety and Lewis-basic substituents ( $\mathrm{X}=\mathrm{sp} 2 \mathrm{O}, \mathrm{S}$ or Se atoms, sp3, sp2 and sp $\mathrm{N}$ atoms, halogen atoms) or halide anions. Such interactions are well described as chalcogen bond interactions, and develop 
preferentially in the prolongation of the covalent $\mathrm{Se}-\mathrm{Se}$ bond, with weaker ones along the $\mathrm{C}-\mathrm{Se}$ bond. The strongest intramolecular interactions lead to Se••X distances much shorter than the van der Waals contact distance, with a reduction ratio down to 0.73 in the most favorable cases. In these situations, a partial charge transfer is deduced from the associated lengthening of the covalent Se-Se bond. Organic selenocyanates form a smaller group of around fifty reported crystal structures, with a notable strengthening of the $\mathrm{ChB}$ in the prolongation of the $\mathrm{NC}-\mathrm{Se}$ bond. This well pronounced difference is exploited to engage poly(selenocyanato) derivatives in anion recognition processes. Albeit the current review is limited to the crystalline solid state, several studies demonstrate that the biochemical activity of diselenides is strongly influenced by the strength of such intramolecular interactions, actually maintained in solution. Similarly, intermolecular $\mathrm{ChB}$, characterized by solid-state NMR, have been also confirmed by solution NMR studies. We show here that ChB interactions in diselenides and selenocyanates, often reported with the passing years every time such short contacts were (eventually) identified, are actually a very general trend, with a high degree of predictability. It should therefore allow everyone to consider it as a novel efficient tool in biochemistry, catalysis or crystal engineering strategies.

\section{References}

${ }^{1}$ R.F. Burk (Ed), Selenium in Biology and Human Health, Springer-Verlag, New York 1994.

${ }^{2}$ A.L. Braga, J. Rafique, PATAI's Chemistry of Functional Groups, Organic Selenium and Tellurium (online version), John Wiley 2013, ch. 22.

${ }^{3}$ B.K. Sarma, G. Mugesh, Chem. Eur. J. 14 (2008) 10603-10614.

${ }^{4}$ A.J. Mukherjee, S.S. Zade, H.B. Singh, R.B. Sunoj, Chem. Rev. 110 (2010) 4357-4416.

${ }^{5}$ H. Bent, Chem. Rev. 68 (1968) 587-648.

${ }^{6}$ N. Ramasubbu, R. Parthasarathy, P. Murray-Rust, J. Am. Chem. Soc. 108 (1986) $4308-4314$.

${ }^{7}$ G.R. Desiraju, R. Parthasarathy, J. Am. Chem. Soc. 111 (1989) 8725-8726.

${ }^{8}$ A. Bondi, J. Phys. Chem. 68 (1964) 441-451.

${ }^{9}$ P. Politzer, J.S. Murray, T. Clark, Phys Chem. Chem. Phys. 12 (2010) 7748-7757.

${ }^{10}$ K. Lamberts, P. Handels, U. Englert, E. Aubert, E. Espinosa, CrystEngComm 18 (2016) $3832-3841$.

${ }^{11}$ O. Makhotkina, J. Lieffrig, O. Jeannin, M. Fourmigué, E. Aubert, E. Espinosa, Cryst. Growth Des. 15 (2015) 3464-3473. 
${ }^{12}$ P. Metrangolo, G. Resnati, Chem. Eur. J. 7 (2001) 2511-2519.

${ }^{13}$ P. Metrangolo, H. Neukirch, T. Pilati, G. Resnati, Acc. Chem. Res. 38 (2005) 386-395.

${ }^{14}$ G.R. Desiraju, P.S. Ho, L. Kloo, A.C. Legon, R. Marquard, P. Metrangolo, P. Politzer, G. Resnati, K. Rissanen, Pure Appl. Chem. 85 (2013) 1711-1713.

${ }^{15}$ G. Cavallo, P. Metrangolo, R. Milani, T. Pilati, A. Priimagi, G. Resnati, G. Terraneo, Chem. Rev. 116 (2016) 2478-2601.

${ }^{16}$ A. Mohajeri, A.H. Pakiari, N. Bagheri, Chem. Phys. Lett. 467 (2009) 393-397.

${ }^{17}$ G. Cavallo, P. Metrangolo, T. Pilati, G. Resnati, G. Terraneo, Cryst. Growth Des. 14 (2014) 2697-2702.

${ }^{18}$ P. Politzer, J.S. Murray, M.C. Concha, J. Mol. Model. 14 (2008) 659-665.

${ }^{19}$ J.S. Murray, G. Resnati, P. Politzer, Faraday Discuss. 203 (2017) 113-130.

${ }^{20}$ P. Scilabra, J.S. Murray, G. Terraneo, G. Resnati, Cryst. Growth Des. 19 (2019) 1149-1154.

${ }^{21}$ C.J. Burchell, P. Kilian, A.M.Z. Slawin, J.D. Woollins, K. Tersago, C. Van Alsenoy, F. Blockhuys, Inorg. Chem. 45 (2006) 710-716.

${ }^{22}$ S. Hauge, K. Maroy, Acta Chem. Scand. 46 (1992) 1166-1169.

${ }^{23}$ R.A. Popa, E. Licarete, M. Banciu, A. Silvestru, Appl. Organomet. Chem. 32 (2018) e4252

${ }^{24}$ T. Kimura, T. Nakahodo, H. Fujihara, E. Suzuki, Inorg. Chem. 53 (2014) 4411-4417.

${ }^{25}$ K. Shimada, A. Moro-oka, A. Maruyama, H. Fujisawa, T. Saito, R. Kawamura, H. Kogawa, M. Sakuraba, Y. Takata, S. Aoyagi, Y. Takikawa, C. Kabuto, Bull. Chem. Soc. Jpn. 80 (2007) 567-577.

${ }^{26}$ C.P. Prabhu, P.P. Phadnis, A.P. Wadawale, K.I. Priyadarsini, V.K. Jain, J. Organomet. Chem. 713 (2012) 42-50.

${ }^{27}$ K.P. Bhabak, G. Mugesh, Chem. Asian J. 4 (2009) 974-983.

${ }^{28}$ S. Kumar, K. Kandasamy, H.B. Singh, R.J. Butcher, New J. Chem. 28 (2004) 640-645.

${ }^{29}$ S. Panda, P.Kr. Dutta, G. Ramakrishna, C.M. Ready, S.S. Zade, J. Organomet. Chem. 717 (2012) 45-51.

${ }^{30}$ G. Mugesh, A. Panda, H.B. Singh, N.S. Punekar, R.J. Butcher, Chem. Commun. (1998) 2227-2228.

${ }^{31}$ Y. Miyake, Y. Nishibayashi, S. Uemura, Bull. Chem. Soc. Jpn. 75 (2002) 2233-2237.

32 A. Pollnitz, C. Silvestru, J.-F. Carpentier, A. Silvestru, Dalton Trans. 41 (2012) 5060-5070.

${ }^{33}$ P.G. Jones, M.C.R. de Arellano, J. Chem. Soc. Dalton Trans. (1996) 2713-2717.

${ }^{34}$ R. Kaur, H.B. Singh, R.P. Patel, J. Chem. Soc. Dalton Trans. (1996) 2719-2726.

${ }^{35}$ A. Pollnitz, A. Rotar, A. Silvestru, C. Silvestru, M. Kulcsar, J. Organomet. Chem. 695 (2010) 2486-2492. 
${ }^{36}$ K.P. Bhabak, G. Mugesh, Chem. Eur. J. 15 (2009) 9846-9854

${ }^{37}$ D. Bhowmick, G. Mugesh, Tetrahedron 68 (2012) 10550-10560.

${ }^{38}$ M. Kulcsar, A. Beleaga, C. Silvestru, A. Nicolescu, C. Deleanu, C. Todasca, A. Silvestru, Dalton Trans. (2007) 2187-2196.

${ }^{39}$ A. Lari, F. Rominger, R. Gleiter, Acta Crystallogr. C65 (2009) o400-o403.

${ }^{40}$ D.M. Freudendahl, M. Iwaoka, T. Wirth, Eur. J. Org. Chem. (2010) 3934-3944.

${ }^{41}$ G. Mugesh, A. Panda, H.B. Singh, N.S. Punekar, R.J. Butcher, J. Am. Chem. Soc. 123 (2001) 839-850.

${ }^{42}$ A. Pollnitz, A. Silvestru, Tetrahedron 71 (2015) 2914-2921.

${ }^{43}$ E.A. Meyers, R.A. Zingaro, N.L.M. Dereu, Z. Krist. Cryst. Mater. 210 (1995) 305-305.

${ }^{44}$ D.M. Freudendahl, M. Iwaoka, T. Wirth, Eur. J. Org. Chem. (2010) 3934-3944.

${ }^{45}$ S. Kumar, S. Panda, H.B. Singh, G. Wolmershauser, R.J. Butcher, Struct. Chem. 18 (2007) $127-132$.

46 T. Chakraborty, K. Srivastava, S. Panda, H.B. Singh, R.J. Butcher, Inorg. Chim. Acta 363 (2010) 2905-2911.

${ }^{47}$ Y. Xu, Q.-C. Dong, H.-B. Tong, X.-H. Wei, Acta Crystallogr. E63 (2007), o4629-o4629

${ }^{48}$ K. Selvakumar, P. Shah, H.B. Singh, R.J. Butcher, Chem. Eur. J. 17 (2011) 12741-12755.

${ }^{49}$ J. Rafique, S. Saba, R.F.S. Canto, T.E.A. Frizon, W. Hassan, E.P. Waczuk, M. Jan, D.F. Back, J.B.T. Da Rocha, A.L. Braga, Molecules 20 (2015) 10095-10109.

${ }^{50}$ S. Patel, Meenakshi, A.S. Hodage, A. Verma, S. Agrawal, A. Yadav, S. Kumar, Dalton Trans. 45 (2016) 4030-4040.

${ }^{51}$ E.M. Takaluoma, T.T. Takaluoma, R. Oilunkaniemi, R.S. Laitinen, Z. Anorg. Allg. Chem. 641 (2015) 772-779.

${ }^{52}$ W. Nakanishi, Y. Tsubomoto, S. Hayashi, RSC Advances 6 (2016) 93195-93204.

${ }^{53}$ W. Nakanishi, S. Hayashi, S. Morinaka, T. Sasamori, N. Tokitoh, New J. Chem. 32 (2008) 1881-1889.

${ }^{54}$ W. Nakanishi, S. Hayashi, S. Toyota, Chem. Commun. (1996) 371-372.

55 Y. Tsubomoto, S. Hayashi, W. Nakanishi, T. Sasamori, N. Tokitoh, Acta Crystallogr. B73 (2017) 265-275.

${ }^{56}$ H.-F. Han, Y.X., Z.-Q. Guo, Y.-H. Zheng, H.-B. Tong, X.-H. Wei, Wuji Huaxue Xuebao (Chin. J. Inorg. Chem.) 25 (2009) 1073.

${ }^{57}$ D.-Z. Niu, L. Yao, Y. Zhang, Z. Kristallogr.-New Cryst.Struct. 230 (2015) 245-246.

${ }^{58}$ A. Feng, Y. Xu, X. Wei, Acta Crystallogr. E66 (2010) o1216.

${ }^{59}$ Z. Guo, Y. Wang, Y. Xu, X. Wei, IUCrData 2 (2017) x170882. 
${ }^{60}$ A. Bedi, S. Debnath, S.S. Zade, Chem. Commun. 50 (2014) 13454-13456.

${ }^{61}$ S. Debnath, S. Chithiravel, S. Sharma, A. Bedi, K. Krishnamoorthy, S.S. Zade, ACS Applied Materials and Interfaces 8 (2016) 18222-18230.

${ }^{62}$ S. Mondal, G. Mugesh, Org. Biomol. Chem. 14 (2016) 9490-9500.

${ }^{63}$ S.M. Aucott, H.L. Milton, S.D. Robertson, A.M.Z. Slawin, J.D. Woollins, Heteroat. Chem. 15 (2004) 530-542.

${ }^{64}$ S. Mondal, G. Mugesh, Chem. Eur. J. 20 (2014) 11120-11128.

${ }^{65}$ D. Manna, G. Mugesh, J. Am. Chem. Soc. 134 (2012) 4269-4279.

${ }^{66}$ A. Sousa-Pedrares, M.L. Duran-Carril, J. Romero, J.A. Garcia-Vazquez, A. Sousa, Inorg. Chim. Acta 363 (2010) 1212-1221.

${ }^{67}$ J.S. Dhau, A. Singh, R. Dhir, J. Organomet.Chem. 696 (2011) 2008-2013.

68 V.P. Singh, Jia-fei Poon, R.J. Butcher, Xi Lu, G. Mestres, M.K. Ott, L. Engman, J. Org. Chem. 80 (2015) 7385-7395.

${ }^{69}$ V.R. Hathwar, K. Prabakaran, R. Subashini, P. Manivel, F.N. Khan, Acta Crystallogr. E64 (2008) 02295.

${ }^{70}$ K.K. Bhasin, E. Arora, A.S. Grover, Jyoti, H. Singh, S.K. Mehta, A.K.K. Bhasin, C. Jacob, J. Organomet. Chem. 732 (2013) 137-141.

${ }^{71}$ J. H. Palmer, G. Parkin, Polyhedron 52 (2013) 658-668.

${ }^{72}$ M. El-khateeb, H .Gorls, W. Weigand, L.R. Almazahreh, Polyhedron 106 (2016) 27-31.

${ }^{73}$ W. Dietzsch, N.V. Duffy, A.M. Lee, B.W. Skelton, A.H. White, Z. Anorg. Allg. Chem. 632 (2006) 2419-2423.

${ }^{74}$ H.-U. Hummel, T. Fischer, D. Gruss, A. Franke, W. Dietzsch, J. Chem. Soc., Dalton Trans. (1992) 2781-2785.

75 A. Taurog, M.L. Dorris, W.-X. Hu, F.S. Guziec, Jr., Biochem. Pharmacol. 49 (1995) 701709.

${ }^{76}$ G. Roy, M. Nethaji, G. Mugesh, J. Am. Chem. Soc. 126 (2004) 2712-2713.

${ }^{77}$ G. Roy, G. Mugesh, J. Am. Chem. Soc. 127 (2005) 15207-15217.

${ }^{78}$ G. Roy, K.P. Bhabak, G. Mugesh, Cryst. Growth Des. 11 (2011) 2279-2286.

${ }^{79}$ G. Roy, M. Nethaji, G. Mugesh, Org. Biomol. Chem. 4 (2006) 2883-2887.

${ }^{80}$ J. Choi, J.H. Ko, I.G. Jung, H.Y. Yang, K.C. Ko, J.Y. Lee, S.M. Lee, H.J. Kim, J.H. Nam, J.R. Ahn, S.U. Son, Chem. Mater. 21 (2009) 2571-2573.

${ }^{81}$ F. Bigoli, F. Demartin, P. Deplano, F.A. Devillanova, F. Isaia, V. Lippolis, M.L. Mercuri, M.A. Pellinghelli, E.F. Trogu, Inorg. Chem. 35 (1996) 3194-3201.

${ }^{82}$ A.C. Villa, M. Nardelli, M.E.V. Tani, Acta Crystallogr. B26 (1970) 1504-1510. 
${ }^{83}$ H.M.K.K. Pathirana, J.H. Reibenspies, E.A. Meyers, R.A. Zingaro, Acta Crystallogr. C47 (1991) 903-904.

${ }^{84}$ D. Jérome, Chem. Rev. 104 (2004) 5565-5591.

${ }^{85}$ M. Fourmigué, P. Batail, Chem. Rev. 104 (2004) 5379-5418.

${ }^{86}$ J.C. Stark, R. Reed, L.A. Acampora, D.J. Sandman, S. Jansen, T. Jones, B.M. Foxman, Organometallics 3 (1984) 732-735.

${ }^{87}$ R.P. Shibaeva, V.F. Kaminskii, Kristallografiya (Russ.) 23 (1978)1183-1188.

${ }^{88}$ R.P. Shibaeva, V.F. Kaminskii, A.I. Kotov, E.B. Yagubskii, M.L. Khidekel, Kristallografiya (Russ.) (Crystallogr.Rep.) 24 (1979) 271-275.

${ }^{89}$ R.P. Shibaeva, V.F. Kaminskii, E.B. Yagubskii, L.A. Kushch, Kristallografiya 28 (1983) 92-95.

${ }^{90}$ R.P. Shibaeva, V.F. Kaminskii, Kristallografiya 28 (1983) 296-302.

${ }^{91}$ R.P. Shibaeva, V.F. Kaminskii, Kristallografiya 29 (1984) 606-609.

${ }^{92}$ I.Y. Shevyakov, L.I. Buravov, L.A. Kushch, E.B. Yagubskii, S.S. Khasanov, L.V. Zorina, R.P. Shibaeva, N.V. Drichko, I. Olejniczak, Koord. Khim. 28 (2002) 487-495.

${ }^{93}$ K. Takimiya, Y. Aso, T. Otsubo, F. Ogura, Bull. Chem. Soc. Jpn. 64 (1991) 2091-2102.

${ }^{94}$ K. Iwasaki, A. Ugawa, A. Kawamoto, Y. Yamashita, K. Yakushi, T. Suzuki, T. Miyashi, Bull. Chem. Soc. Jpn. 65 (1992) 3350-3357.

${ }^{95}$ L.A. Acampora, B.S. Elman, D.J. Sandman, S. Jansen, M.T. Jones, R.D. Rataiczak, B.M. Foxman, Inorg. Chem. 28 (1989) 1579-1582.

${ }^{96}$ J. Lieffrig, O. Jeannin, A. Frąckowiak, I. Olejniczak, R. Świetlik, S. Dahaoui, E. Aubert, E. Espinosa, P. Auban-Senzier, M. Fourmigué, Chem. Eur. J. 19 (2013) 14804-14813.

${ }^{97}$ P.G. Jones, C. Wismach, G. Mugesh,W.-W. du Mont, Acta Cryst. E58 (2002) o1298-o1300.

${ }^{98}$ K. Maartmann-Moe, G.O. Nevstad, J. Songstad, Acta Chem. Scand. A40 (1986) 182-189.

${ }^{99}$ P. Rakesh, H.B. Singh, R.J. Butcher, Organometallics 32 (2013) 7275-7282.

${ }^{100}$ Hui Wang, Ju Liu, Weizhou Wang, Phys. Chem. Chem. Phys. 20 (2018) 5227-5234.

101 J. George, V.L. Deringer, R. Dronskowski, J. Phys. Chem. A 118 (2014) 3193-3200.

102 N.A. Barnes, S.M. Godfrey, R.T.A. Halton, I. Mushtaq, S. Parsons, R.G. Pritchard, M. Sadler, Polyhedron 26 (2007) 1053-1060.

${ }^{103}$ W.S. McDonald, L.D. Pettit, J. Chem. Soc. A (1970) 2044-2046.

104 T.M. Klapötke, B. Krumm, K. Polborn, Eur. J. Inorg. Chem. (1999) 1359-1366.

105 T.M. Klapotke, B. Krumm, P. Mayer, H. Piotrowski, M. Vogt, Z. Anorg. Allg. Chem. 629 (2003) 1117-1123.

${ }^{106}$ K. Maartmann-Moe, K.A. Sanderud, J. Songstad, Acta Chem. Scand. A 38 (1984) 187-200. 
${ }^{107}$ S.L.W. McWhinnie, A.B. Brooks, I. Abrahams, Acta Cryst. C 54 (1998) 126-128.

${ }^{108}$ H.-T. Huynh, O. Jeannin, M. Fourmigué, Chem. Commun. 53 (2017) 8467-8469

${ }^{109}$ A. Lari, R. Gleiter, F. Rominger, Eur. J. Org. Chem. (2009) 2267-2274.

110 O. Jeannin, H.-T. Huynh, A.M.S. Riel, M. Fourmigué, New J. Chem. 42 (2018) 10502-10509.

${ }^{111}$ D.B. Werz, F.R. Fischer, S.C. Kornmayer, F. Rominger, R. Gleiter, J. Org. Chem. 73 (2008) 8021-8029.

112 R. Luboradzki, CSD Priv. Commun. (2015)

${ }^{113}$ S.J. Dunne, L.A. Summers, E.I. von Nagy-Felsobuki, M.F. Mackay, Acta Cryst. C50 (1994) 971-974.

${ }^{114}$ A.M.S. Riel, H.-T. Huynh, O. Jeannin, O. Berryman, M. Fourmigué, Cryst Growth Des. 19 (2019) 1418-1425.

115 A.M.S. Riel, O. Jeannin, O.B. Berryman, M. Fourmigué Acta Cryst. B75 (2019) 34-38.

${ }^{116}$ H.-T. Huynh, O. Jeannin, M. Fourmigué, Chem. Commun. 53 (2017) 8467-8469.

117 V. Kumar, C. Leroy, D.L. Bryce, CrystEngComm 20 (2018) 6406-6411.

${ }^{118}$ M. Fourmigué, Acta Cryst. B73 (2017) 138-139.

119 J. Lieffrig, O. Jeannin, M. Fourmigué, J. Am. Chem. Soc. 135 (2013) 6200-6210. 


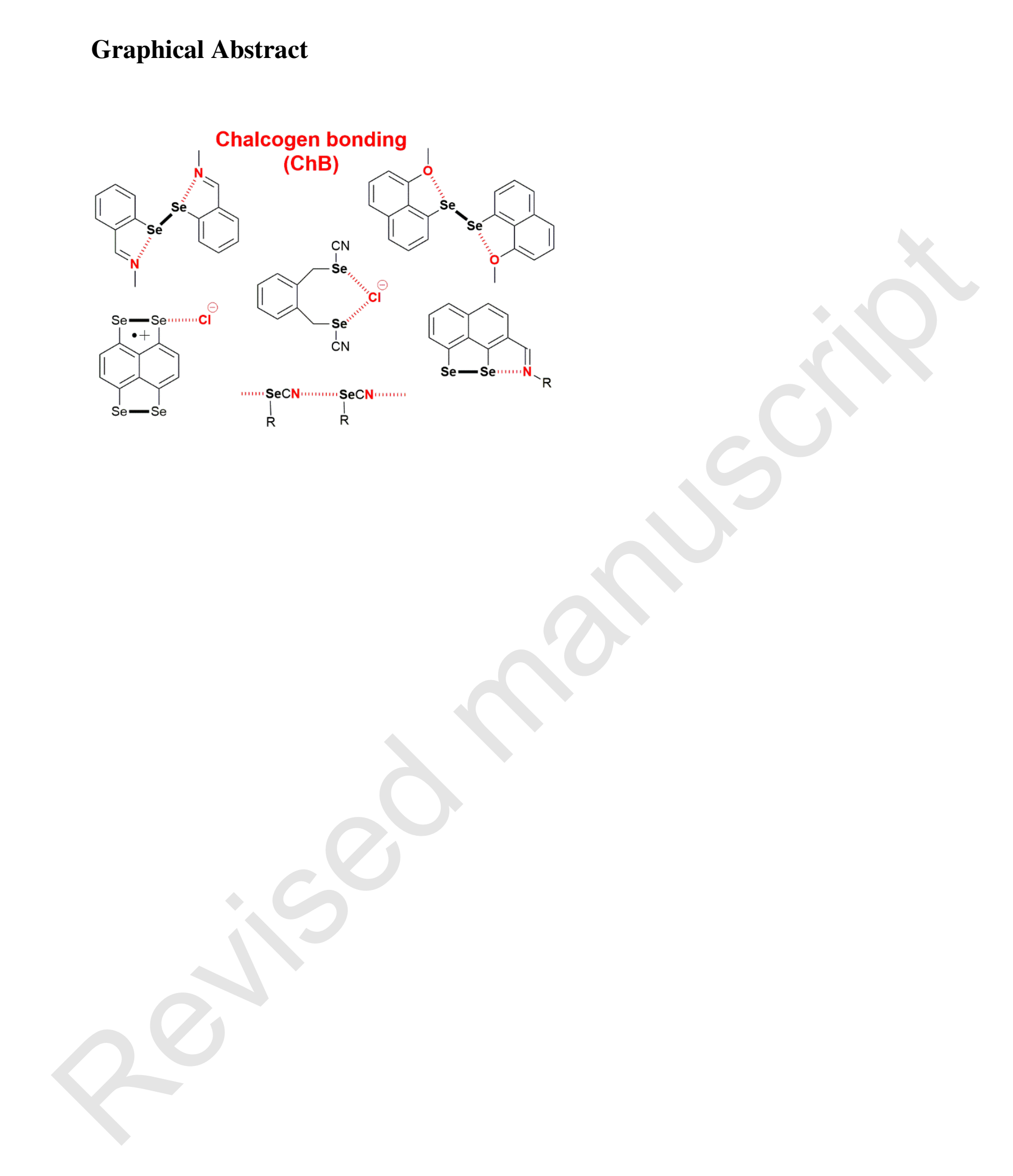

